\title{
NEURAL STEM/PROGENITOR CELL TRANSPLANTATION FOR SPINAL CORD INJURY TREATMENT; A SYSTEMATIC REVIEW AND META-ANALYSIS
}

\author{
M. YOUSEFIFARD, ${ }^{a}$ V. RAHIMI-MOVAGHAR, ${ }^{b}$ \\ F. NASIRINEZHAD, ${ }^{\circ} M$. BAIKPOUR, ${ }^{d}$ S. SAFARI, ${ }^{e}$ \\ S. SAADAT, ${ }^{b}$ A. MOGHADAS JAFARI, ${ }^{f}$ H. ASADY, ${ }^{\mathrm{g}}$ \\ S. M. T. RAZAVI TOUSI ${ }^{a}$ AND M. HOSSEINI ${ }^{\mathrm{b}, h, i *}$ \\ ${ }^{a}$ Department of Physiology, School of Medicine, Tehran University \\ of Medical Sciences, Tehran, Iran \\ ${ }^{\mathrm{b}}$ Sina Trauma and Surgery Research Center, Tehran University \\ of Medical Sciences, Tehran, Iran \\ c Physiology Research Center, Department of Physiology, \\ Iran University of Medical Sciences, Tehran, Iran \\ ${ }^{\mathrm{d}}$ Department of Medicine, School of Medicine, Tehran University \\ of Medical Sciences, Tehran, Iran \\ e Department of Emergency Medicine, Shohadaye Tajrish \\ Hospital, Shahid Beheshti University of Medical Sciences, Tehran, \\ Iran \\ ${ }^{\mathrm{f}}$ Department of Emergency Medicine, School of Medicine, \\ Bushehr University of Medical Sciences, Bushehr, Iran \\ ${ }^{9}$ Department of Occupational Health Engineering, Faculty of \\ Public Health, Tehran University of Medical Sciences, Tehran, Iran \\ ${ }^{\mathrm{h}}$ Department of Epidemiology and Biostatistics, School of \\ Public Health, Tehran University of Medical Sciences, Tehran, Iran \\ i Pediatric Chronic Kidney Disease Research Center, Tehran \\ University of Medical Sciences, Tehran, Iran
}

\begin{abstract}
Despite the vast improvements of cell therapy in spinal cord injury treatment, no optimum protocol has been developed for application of neural stem/progenitor cells. In this regard, the present meta-analysis showed that the efficacy of the neural stem/progenitor cell (NSPC) transplantation depends mainly on injury model, intervention phase, transplanted cell count, immunosuppressive use, and probably stem cell source. Improved functional recovery post NSPC transplantation was found to be higher in transection and contusion models. Moreover, NSPC transplantation in acute phase of spinal injury was found to have better functional recovery. Higher doses $\left(>3 \times 10^{6} \mathrm{cell} / \mathrm{kg}\right)$ were also shown to be optimum for transplantation, but immunosuppressive agent administration negatively affected the motor function recovery. Scaffold use in NSPC transplantation could also effectively raise functional recovery. (c) 2016 Published by Elsevier Ltd. on behalf of IBRO.
\end{abstract}

\footnotetext{
${ }^{*}$ Correspondence to: M. Hosseini, Department of Epidemiology and Biostatistics School of Public Health, Tehran University of Medical Sciences, Poursina Avenue, Tehran, Iran. Tel: +98-2188989125; fax: + 98-2188989127.

E-mail address: mhossein110@yahoo.com (M. Hosseini).

Abbreviations: NSPC, neural stem/progenitor cell; SCI, Spinal cord injury; SMD, standardized mean difference.
}

Key words: spinal cord injuries, neural stem cells, functional recovery, neuropathic pain.

\section{INTRODUCTION}

Spinal cord injury (SCl) which is one of the most dangerous nervous system disorders, commonly affects younger population, and causes persistent and longterm disabilities. Unfortunately, about $90 \%$ of the patients suffer from long-term motor dysfunctions and approximately $78 \%$ experience moderate to severe pain. $\mathrm{SCl}$ and its complications impose great direct and indirect financial burdens; the annual treatment cost for each patient is estimated to be 26,270 dollars (Mann et al., 2013).

$\mathrm{SCl}$ is regarded as one of the main causes of motor dysfunction and neuropathic pain. There is no cure for it and most of the therapeutic modalities are only symptomatic (Finnerup, 2013; Sharp et al., 2012; Kumru et al., 2013; Nasirinezhad et al., 2015b). Pharmacotherapy holds the base of current treatment with little influence on functional recovery with only $30-40 \%$ decrease in neuropathic pain symptoms (Finnerup et al., 2005; Backonja et al., 2006). Besides, numerous medication adverse side effects are the major obstacles for the long-term use (Marineo et al., 2012; Hosseini et al., 2014; Nasirinezhad et al., 2015a). Motor dysfunction and neuropathic pain will persist unless the injured region recovers or pain control pathways reinforce. However, neurogenesis rarely occurs in central nervous system and self-healing in injured cells is rather limited. Accordingly, researchers are investigating to find methods to improve cell restoration. Currently, cell transplantation is considered as an appropriate choice for treating SCls. According to the recent studies, cell therapy can create new neural connections which would then lead to neuropathic pain alleviation and improved functional recovery (Guenot et al., 2007; Hama and Sagen, 2007).

Various cell populations can be used for $\mathrm{SCl}$ treatment. Survival and differentiation of the transplanted cells are mainly influenced by host-related factors as well as innate properties. For instance, having been injected in brain neurogenic regions, such as the hippocampus or sub-ventricular zones, neural stem/progenitor cells (NSPCs) exhibit acceptable differentiation (Sun et al., 2011); but when transplanted in other parts of the nervous system, low survival and differentiation are observed (Mark Richardson et al., 2005). 
Based on these findings, one may conclude that in vivo transplanted cell outcome is determined by innate characteristics and transplantation location.

Studies have shown that NSPCs are subject to renewal and can produce main neural cell phenotypes (neurons, oligodendrocytes and astrocytes) after transplantation in injured spinal cord (Tarasenko et al., 2007). These cells can also modulate immune and inflammatory responses (Lee et al., 2008a; Bacigaluppi et al., 2009; Ottoboni et al., 2015). Hence, as proposed by many studies, NSPCs may be the best choice in transplantation treatment for physiologic repair of the lesion, functional recovery and neuropathic pain relief in patients with SCls (Bottai et al., 2008; Abematsu et al., 2010; Amemori et al., 2013). On the other hand, some researchers believe that these cells are not significantly effective in spinal lesion treatment (Macias et al., 2006; Nutt et al., 2013). These discrepancies might be due to the differences in treatment protocols, number of transplanted cells, application of co-treatments, source of extracted cells, and etc. In this regard, a systematic review showed that no consensus has been reached on the optimal source of NSPCs and their application in various models of spinal cord injuries, severity of injuries, and treatment protocol (Tetzlaff et al., 2011).

So, there is no reliable and comprehensive review to judge whether NSPC transplantation is really a suitable therapeutic protocol for SCls. Conceivably, a metaanalysis seems to be an appropriate alternative solution for this problem. Recently, few meta-analyses were performed on the subject but none evaluated neural stem cells. In the previous meta-analysis we showed that bone marrow-derived mesenchymal stem cell application improved mechanical allodynia but had no significant effects on hyperalgesia (Hosseini et al., 2015). Accordingly, this study aimed to conduct a systematic review and meta-analysis to assess the efficacy of NSPCs on functional recovery and neuropathic pain relief in animal models of SCl.

\section{METHODS}

\section{Search strategy}

Two independent reviewers carried out an extended search in electronic databases of Medline (via PubMed), EMBASE (via OvidSP), CENTRAL, SCOPUS, Web of Science (BIOSIS), and ProQuest finding papers published until the end of December, 2015. Search strategy was based on keywords related to "neural stem cells", "neural progenitor stem cell" and "neural precursor cell" in combination with terms related to "spinal cord injuries". The combined terms in two databases of Medline and EMBASE are presented in Panel 1. In order to prevent omission of related studies, keywords were chosen as extensive as possible. Keywords were extracted from Mesh, EMTREE, and via manual search in titles and abstracts of the articles.

Additionally, PubMed search was not limited to Medline. Archived articles in PubMed Central were also screened. In order to further include non-indexed reports, search was also conducted in Google search engine and Google Scholar. Two strategies were
Panel 1. Keywords used for search in MEDLINE and EMBASE databases

\begin{tabular}{|c|c|}
\hline Database & Search terms \\
\hline Medline (PubMed) & $\begin{array}{l}\text { "Neural stem cells"[MeSH] OR } \\
\text { (Progenitor cell"[tiab] OR Neural } \\
\text { progenitor stem cell*[tiab] OR Neural } \\
\text { precursor cell*[tiab] OR Spinal cord stem } \\
\text { cell }^{*}[\text { tiab] OR Brain stem cell*[tiab] OR } \\
\text { Brain derived stem cell*[tiab] OR Spinal } \\
\text { derived stem cell*[tiab] OR Embryonic- } \\
\text { derived neural stem cell*[tiab] OR } \\
\text { Embryonic neural stem cel*|[tiab] OR } \\
\text { Induced pluripotent stem cell*[tiab] OR } \\
\text { NSC[tiab] OR NSPC[tiab]) AND "Spinal } \\
\text { cord injuries"[MeSH] OR (Spinal cord } \\
\text { contusion[tiab] OR Spinal cord transection } \\
\text { [tiab] OR Injured spinal cord[tiab] OR } \\
\text { Spinal Cord Traum*[tiab] OR Spinal cord } \\
\text { Hemisection[tiab] OR Spinal compression } \\
\text { [tiab] OR Traumatic Myelopath*[tiab] OR } \\
\text { Spinal Cord Laceratio*[tiab] OR Post- } \\
\text { Traumatic Myelopath*[tiab]) }\end{array}$ \\
\hline EMBASE (OvidSP) & $\begin{array}{l}\text { exp Neural Stem Cells/ or (Neural Stem } \\
\text { Cells or Progenitor cells or Neural } \\
\text { progenitor stem cell or Neural precursor } \\
\text { cell or Embryonic-derived neural stem cell } \\
\text { or Embryonic neural stem cell or Induced } \\
\text { pluripotent stem cell\$ or NSC or NSPC).ti, } \\
\text { ab. and exp Spinal cord injuries/ or (Spinal } \\
\text { cord injur\$ or Spinal cord contusion or } \\
\text { Spinal cord transection or Injured spinal } \\
\text { cord or Spinal Cord Traum\$ or Spinal cord } \\
\text { Hemisection or Spinal compression or } \\
\text { Traumatic Myelopath\$ or Spinal Cord } \\
\text { Laceration or Post-Traumatic Myelopath } \\
\$ \text { ).ti,ab. }\end{array}$ \\
\hline
\end{tabular}

pursued to gather gray literature: (a) authors of related articles were contacted via email to ask for unpublished data or dissertations and unrecorded data, (b) ProQuest database was meticulously searched for related dissertations. In cases where the article was not available online, the author was contacted. If there were no answers, a reminder was sent to the author, one week later. In case of no reply, other authors of the article were contacted through social networks including ResearchGate and Linkedln, asking for the data. Two studies were obtained using this method.

To find additional articles, hand-search was performed in the bibliographies of relevant studies which yielded inclusion of two more articles. Moreover, journal hand-searching was also carried out. To do so, gathered studies were entered the EndNote $\mathrm{X} 7$ software and a list of highly focused journals with the highest number of articles on the subjects of stem cell therapy, neuroscience and spine was provided. All issues of the selected journals were manually screened and three more articles added to this strategy.

\section{Inclusion criteria}

In the present survey, all controlled studies evaluating neural stem cell effects on functional recovery and sensory improvement after $\mathrm{SCls}$ were included. No 
temporal or linguistic restrictions were considered. Included studies were in vivo animal models (nonhuman), in which $\mathrm{SCl}$ was induced through compression, contusion, hemisection or transection models with no age, gender or phylum restrictions. A four-week gap during the follow up period was considered as exclusion criterion, since the minimum amount of time needed for the cell therapy effects on functional recovery and sensory improvement is three to four weeks. Surveys lacking control groups (sham, saline-treated or vehicle treated groups) were also excluded.

\section{Quality assessment and data extraction}

Duplicate articles were removed using EndNote software (version X7, Thomson Reuters, 2011). Two of the authors (M.Y and S.S) independently examined the titles and abstracts of the articles and screened potentially eligible studies. Then, study full-texts were investigated and surveys met with the inclusion criteria were selected. Data extraction performed by researchers blinded to the author, journal and organization of the studies. Data recorded in a checklist designed based on PRISMA statement guidelines (Moher et al., 2009). The data included: (i) animal characteristics (number, recipient species, gender, weight), (ii) $\mathrm{SCl}$ model details including injury model, severity and location, (iii) cell therapy protocol as time interval between injury and treatment, delivery route, antibiotics application and immunosuppressive agents use, transplanted cell count, (iv) graft type (allogeneic or xenogeneic), (v) extracted neural stem cells characteristics including donor species, embryonic or adult source, (vi) follow-up duration (vii) outcome (motor function and neuropathic pain symptoms), and (viii) probable biases. Reviewers' disagreements were discussed with a third reviewer and settled through mutual cooperation (93\% agreement). For quality assessment, each study was assigned a score of good, fair or poor, based on a 19-item checklist recommendation of Antonic et al. (Antonic et al., 2013) and Hassannejad et al. (Hassannejad et al., 2015) studies.

\section{Data synthesis}

Outcomes assessed included functional recovery and neuropathic pain symptoms (allodynia and hyperalgesia). Data were recorded as mean and standard error. In case data were presented as charts, the data extraction method proposed by Sistrom and Mergo was utilized (Sistrom and Mergo, 2000). When outcomes were reported in multiple stages of the survey, only the last reported figures were included. If multiple reports were given for the same population, the study with the largest sample size and the longest follow-up period would be included. In non-extracted data studies, the author was contacted and asked for the required information.

\section{Statistical analysis}

Data were summarized and entered in the STATA 11.0 statistical software in mean and standard deviation formats. In case standard errors were presented, standard deviations were calculated according to the study sample size. For each individual comparison, based on Hedges' g, a standardized mean difference (SMD) was calculated with a confidence interval of $95 \%$ $(95 \% \mathrm{Cl})$ and then a pooled effect size was presented. Publication bias was examined through Egger's and Begg's tests and funnel plots drawing (Egger et al., 1997). Heterogeneity was assessed using Chi-squared and $l^{2}$ tests. A $p$ value of 0.1 or less and an $l^{2}$ greater than $50 \%$ were considered as existence of heterogeneity. Fixed effect model was used for homogenous studies, and if the positive heterogeneity held, subgroup analysis was performed to determine its source. Random effects model was fitted for cases of unidentified heterogeneity source. Subgroup analysis was carried out based on animal gender, recipient species (mice, rat, and so), injury model (contusion, compression, hemisection, transection), location (cervical, thoracic, lumbar), and severity (moderate, severe), stem cell origin (brain, spine, other), intervention phase (acute, sub-acute, chronic), delivery route (intra spinal and so), graft type (allogeneic, xenogeneic), stem cell type (wild type NSPC; induced pluripotent stem cell-derived NSPC), number of transplanted cells, donor species (mice, rat, human, other), and age range (fetal, newborn, adult), co-treatment use, antibiotic, or immunosuppressive agents, observer neutrality, and follow-up period (less than 8 weeks, equal to, or more than 8 weeks). Eight weeks follow up was set based on the functional recovery duration in which plateau is being reached. It is worth mentioning that meta-analyses were carried out only if the data were reported by at least three studies.

\section{RESULTS}

\section{Characteristics of the included studies}

Search in electronic sources yielded 10,153 nonduplicated studies. Screening through titles and abstracts found 298 articles, 81 of which met the inclusion criteria. A total of 74 studies were included in the meta-analysis at last (Teng et al., 2002; Cummings et al., 2005; Hofstetter et al., 2005; Iwanami et al., 2005; Okada et al., 2005; Pallini et al., 2005; KarimiAbdolrezaee et al., 2006, 2010; Macias et al., 2006; Ziv et al., 2006; Guo et al., 2007, 2012; Parr et al., 2007, 2008a,b; Tarasenko et al., 2007; Zhang et al., 2007; Bottai et al., 2008; Lowry et al., 2008; Pan et al., 2008; Hooshmand et al., 2009; Kumagai et al., 2009; Lee et al., 2009; Abematsu et al., 2010; Chen et al., 2010; $\mathrm{Hu}$ et al., 2010; Johnson et al., 2010; Salazar et al., 2010; Tsuji et al., 2010; Yamane et al., 2010; Du et al., 2011; Kim et al., 2011, 2012; Nori et al., 2011; Wang et al., 2011, 2014; Xu et al., 2011; Yasuda et al., 2011; Cheng et al., 2012; Cusimano et al., 2012; Fujimoto et al., 2012; Gu et al., 2012; Kobayashi et al., 2012; Lu et al., 2012, 2014; Amemori et al., 2013, 2015; He et al., 2013; Kumamaru et al., 2013; Luo et al., 2013; Nishimura et al., 2013; Nutt et al., 2013; Park et al., 2013; Piltti et al., 2013a,b; Sontag et al., 2013; van Gorp et al., 2013; Xia et al., 2013; Yang et al., 2013; Hong et al., 2014; Hwang et al., 2014; Iwasaki et al., 2014; Nemati et al., 2014; Ormond et al., 2014; 
Sharp et al., 2014; Yuan et al., 2014; Iwai et al., 2015; Liu et al., 2015; Pomeshchik et al., 2015; Romanyuk et al., 2015; Salewski et al., 2015a,b; Yao et al., 2015; Yokota et al., 2015). Search flowchart and selection methods are presented in Fig. 1. These studies comprised 125 separate experiments whose data were included in the final analysis. In 60 studies, subject motor function was only evaluated (Cummings et al., 2005; Iwanami et al., 2005; Okada et al., 2005; Pallini et al., 2005; Ziv et al., 2006; Guo et al., 2007, 2012; Parr et al., 2007, 2008a,b; Tarasenko et al., 2007; Zhang et al., 2007; Bottai et al., 2008; Lowry et al., 2008; Pan et al., 2008; Hooshmand et al., 2009; Kumagai et al., 2009; Lee et al., 2009; Abematsu et al., 2010; Chen et al., 2010; Johnson et al., 2010; Tsuji et al., 2010; Yamane et al., 2010; Du et al., 2011; Kim et al., 2011, 2012; Nori et al., 2011; Wang et al., 2011, 2014; Xu et al., 2011; Yasuda et al., 2011; Cheng et al., 2012; Cusimano et al., 2012; Fujimoto et al., 2012; Gu et al., 2012; Kobayashi et al., 2012; Lu et al., 2012, 2014; Amemori et al., 2013, 2015; He et al., 2013; Kumamaru et al., 2013; Nishimura et al., 2013; Nutt et al., 2013; Park et al., 2013; Xia et al., 2013; Yang et al., 2013; Hong et al., 2014; Hwang et al., 2014; Iwasaki et al., 2014; Nemati et al., 2014; Ormond et al., 2014; Sharp et al., 2014; Yuan et al., 2014; Iwai et al., 2015; Liu et al., 2015; Pomeshchik et al., 2015; Romanyuk et al., 2015; Yokota et al., 2015; Salewski et al., 2015a) and in five just sensory status was assessed (Hu et al., 2010; Luo et al., 2013; Piltti et al., 2013a,b; Yao et al., 2015). These elements were both simultaneously assessed in 10 surveys
(Teng et al., 2002; Hofstetter et al., 2005; KarimiAbdolrezaee et al., 2006, 2010; Macias et al., 2006; Salazar et al., 2010; Sontag et al., 2013; van Gorp et al., 2013; Amemori et al., 2015; Salewski et al., 2015b). Characteristics of the included studies are presented in Table 1.

Gathered data from 2537 animals (1204 in control group and 1333 in the treatment group) were pooled and analyzed together. Evaluation was conducted on 101 female and 24 male experimental animals. Contusion model was the most commonly used $\mathrm{SCl}$ induction model performed on 68 experiments, followed by 24 transection, 15 clip compression, 14 hemisection, and four balloon compression experiments. Experimentinduced injuries were severe in half and moderate in the other half. Mean time interval between injury and treatment was $9.3 \pm 11.3$ days (ranged from 1 to 56 days). In 40 experiments transplantation was performed right after injury induction (acute phase), in 74 procedures were 3-10 days apart (sub-acute phase), and in 11 this gap was equal to or more than two weeks (chronic phase). Intra-spinal transplantation was carried out in 114 experiments. Graft type was allogeneic in 77 experiments. The number of transplanted cells ranged from $1 \times 10^{5}$ to $4 \times 10^{7}$ cells per kilograms of the animals' body weight. Quality assessment of the included studies is presented in Table 2.

\section{Meta-analysis}

Efficacy of neural stem cell transplantation on functional recovery. In literature review, 69 studies including

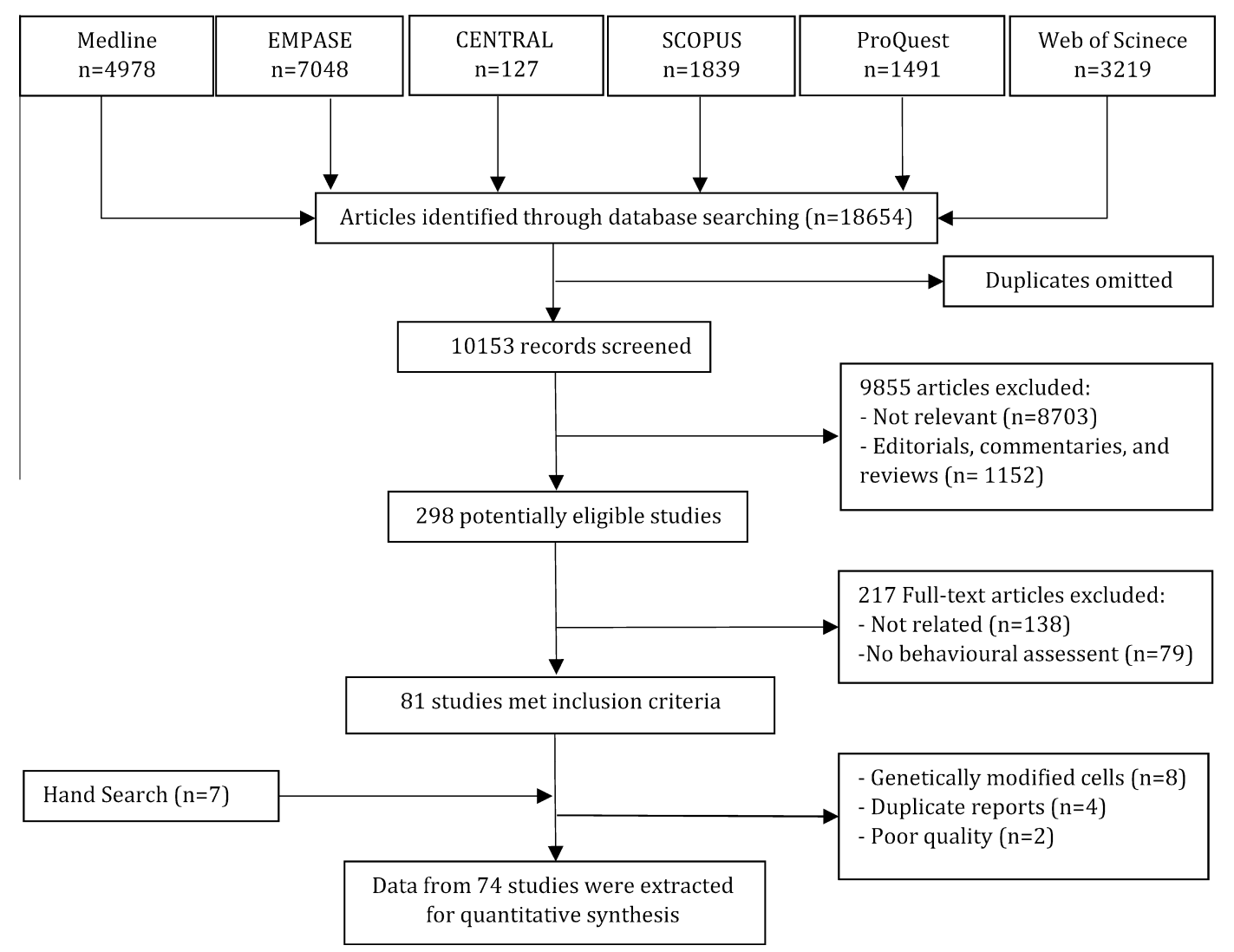

Fig. 1. Flowchart of including studies in the meta-analysis. 
Table 1. Characteristics of included studies

\begin{tabular}{|c|c|c|c|c|c|}
\hline Author, Year & $\begin{array}{l}\text { Gender/Species/Weight } \\
\text { (gr) }\end{array}$ & Model/Location of injury/Severity & $\begin{array}{l}\text { Cell source/Donor/Graft/Dose/Type/Intervention time } \\
\text { (day) }\end{array}$ & $\begin{array}{l}\text { Immunosuppressive/ } \\
\text { Antibiotic/Blinding }\end{array}$ & $\begin{array}{l}\text { Follow up } \\
\text { (week) }\end{array}$ \\
\hline Abematsu et al., 2010 & Male/Mice/37-45 & Contusion/T9-T10/Severe & Brain/Fetus/Mice/IS/1 × 106/Allogeneic/7 & Yes/Yes/Yes & 8 \\
\hline Amemori et al., 2013 & Male/Rat/270-300 & $\begin{array}{l}\text { Balloon compression/T8-T9/ } \\
\text { Moderate }\end{array}$ & Spine/Fetus/Human/IS/5 × 105/Xenogeneic/7 & Yes/Yes/Yes & 8 \\
\hline Amemori et al., 2015 & Male/Rat/270-300 & Balloon compression/T8/Moderate & Lung/Fetus/Human/IS and IT/5 $\times 105 /$ Xenogeneic/7 & Yes/Yes/Yes & 8 \\
\hline Bottai et al., 2008 & Male/Mice/29-30 & Contusion/T8/Moderate & Brain/Adult/Mice/IS/1 × 106/Allogeneic/1 & No/No/Yes & 8 \\
\hline Chen et al., 2010 & Female/Rat/250-300 & Hemisection/T9/Severe & Spine/Fetus/Rat/IS/2 × 105/Allogeneic/1 & No/No/Yes & 24 \\
\hline Cheng et al., 2012 & Female/Rat/200-350 & Contusion/T10/Moderate & Brain/Fetus/Human/IT/5 × 105/Xenogeneic/1 & No/Yes/Yes & 7 \\
\hline Cummings et al., 2005 & Female/Mice/18-22 & Contusion/T8/Moderate & Brain/Fetus/Human/IS/7.5 × 104/Xenogeneic/9 & No/No/Yes & 16 \\
\hline Cusimano et al., 2012 & Male/Mice/20-22 & Contusion/T11/Severe & $\begin{array}{l}\text { Brain/Adult/Mice/IS/7.5 } \times 104 \text { or } 1.5 \times 105 / \text { Allogeneic/ } 7 \\
\text { or } 21\end{array}$ & No/Yes/Yes & 8 \\
\hline Du et al., 2011 & Female/Rat/220-250 & Transection/T10/Severe & Brain/Newborn/Rat/IS/1.5 × 105/Allogeneic/1 & No/Yes/Yes & 8 \\
\hline Fujimoto et al., 2012 & Female/Mice/18-20 & Contusion/T10/Moderate & Skin fibroblast/Adult/Human/IS/5 $\times 105 /$ Xenogeneic/7 & No/Yes/Yes & 9 \\
\hline Gu et al., 2012 & Male/Rat/200-250 & Transection/T10/Severe & Brain/Fetus/Mice/IS/2 × 104/Xenogeneic/1 & No/No/No & 4 \\
\hline Guo et al., 2007 & Female/Rat/200-220 & Transection/T9-T10/Severe & Brain/Newborn/Rat/IS/4 × 106/Allogeneic/1 & No/Yes/No & 8 \\
\hline Guo et al., 2012 & Female/Rat/200-300 & Transection/T8/Severe & Brain/Adult/Rat/IS/1.5 × 106/Allogeneic/1 & Yes/Yes/Yes & 12 \\
\hline He et al., 2013 & Male/Rat/200-250 & Transection/T10/Severe & Brain/Fetus/Mice/IS/3 × 105/Xenogeneic/1 & No/No/Yes & 4 \\
\hline Hofstetter et al., 2005 & Female/Rat/250 & Contusion/T8-T9/Moderate & Brain/Adult/Rat/IS/1 × 105/Allogeneic/7 & No/No/Yes & 9 \\
\hline Hong et al., 2014 & Female/rat/230-250 & Contusion/T8-T9/Moderate & $\begin{array}{l}\text { Embryonic fibroblasts/Fetus/Mice/IS/1 × 106/ } \\
\text { Xenogeneic/9 }\end{array}$ & Yes/No/Yes & 12 \\
\hline Hooshmand et al., 2009 & Female/Mice/17-20 & Contusion/T8/Moderate & Brain/Fetus/Human/IS/7.5 × 104/Xenogeneic/9 & Yes/No/Yes & 16 \\
\hline Hu et al., 2010 & Female/Mice/20-22 & Contusion/T8/Moderate & Whisker follicle/Adult/Mice/IS/1.4 × 105/Allogeneic/1 & $\mathrm{No} / \mathrm{No} / \mathrm{No}$ & 4 \\
\hline Hwang et al., 2014 & Male/Rat/250-300 & Contusion/T9/Severe & Spine/Fetus/Rat/IS/1 × 105/Allogeneic/7 & No/No/Yes & 7 \\
\hline Iwai et al., 2015 & $\begin{array}{l}\text { Female/Marmoset/300- } \\
350\end{array}$ & Contusion/C5/Severe & Brain/Fetus/Marmoset/IS/1 × 106/Allogeneic/14 & Yes/Yes/No & 12 \\
\hline Iwanami et al., 2005 & $\begin{array}{l}\text { Female/Marmoset/280- } \\
350\end{array}$ & Contusion/C5/Severe & Brain/Fetus/Human/IS/1 × 106/Xenogeneic/9 & Yes/Yes/No & 8 \\
\hline Iwasaki et al., 2014 & Female/Rat/250 & Compression/C6-C7/Moderate & Brain/Adult/Mice/IS/4 × 105/Xenogeneic/14 & Yes/Yes/Yes & 10 \\
\hline Johnson et al., 2010 & Female/Rat/250-275 & Hemisection/T9/Severe & Brain/Fetus/Mice/IS/1 × 105/Xenogeneic/14 & Yes/Yes/Yes & 8 \\
\hline $\begin{array}{l}\text { Karimi-Abdolrezaee et al., } \\
2010\end{array}$ & Female/Rat/250 & Compression/T7/Moderate & Brain/Adult/Mice/IS/4 × 105/Xenogeneic/49 & Yes/Yes/Yes & 9 \\
\hline $\begin{array}{l}\text { Karimi-Abdolrezaee et al., } \\
\quad 2006\end{array}$ & Female/Rat/250 & Compression/T6-T8/Moderate & Brain/Adult/Mice/IS/3-4 × 105/Xenogeneic/14 & Yes/No/Yes & 6 \\
\hline Kim et al., 2011 & Female/Rat/250-300 & Transection/T8/Severe & Brain/Adult/Rat/IS/2.5 × 105/Allogeneic/1 & Yes/No/Yes & 6 \\
\hline Kim et al., 2012 & Male/Rat/250 & Compression/T9/Moderate & Brain/Fetus/Mice/IS/3 × 105/Xenogeneic/1 & Yes/No/Yes & 6 \\
\hline Kobayashi et al., 2012 & Female/Marmoset/300 & Contusion/C5/Severe & Skin fibroblast/Adult/Human/IS/1 × 106/Xenogeneic/9 & Yes/Yes/Yes & 11 \\
\hline Kumagai et al., 2009 & Female/Mice/20-22 & Contusion/T10/Moderate & Brain/Fetus/Mice/IS/5 × 105/Allogeneic/9 & No/No/Yes & 6 \\
\hline Kumamaru et al., 2013 & Female/Mice/20-30 & Contusion/T10/Moderate & Spine/Fetus/Mice/IS/5 $\times 105 /$ Allogeneic/ 1 or 7 or 13 & No/No/Yes & 6 \\
\hline Lee et al., 2009 & / dogs $/ 25,000-32,000$ & Hemisection/L2/Severe & Brain/Fetus/Human/IS/1 × 107/Xenogeneic/1 & No/Yes/Yes & 12 \\
\hline Liu et al., 2015 & Female/Rat/220-250 & Transection/T10/Severe & $\begin{array}{l}\text { Embryonic fibroblast/ Fetus/Mice/IS/ } 1 \times 106 / \\
\text { Xenogeneic/1 }\end{array}$ & Yes/Yes/Yes & 10 \\
\hline Lowry et al., 2008 & Female/Mice/10_12 & Hemisection/T8-T9/Severe & Spine/Fetus/Mice/IS/1 × 105/Allogeneic/1 & No/No/Yes & 4 \\
\hline Lu et al., 2012 & Female/Rat/160-200 & Transection/T3/Severe & $\begin{array}{l}\text { Spine/Fetus/Rat and Human/IS/1.4 × 106/Xenogeneic/7 } \\
\text { and } 14\end{array}$ & No/No/Yes & 6 \\
\hline Lu et al., 2014 & Female/Rat/160-200 & Hemisection/C5/Severe & Skin/Adult/Human/IS/1.4 × 106/Xenogeneic/14 & No/No/Yes & 12 \\
\hline Luo et al., 2013 & Female/Rat/180-250 & Transection/T7-T9/Severe & Brain/Adult/Rat/IS/3 × 105/Allogeneic/1 & Yes/Yes/Yes & 4 \\
\hline
\end{tabular}




\begin{tabular}{|c|c|c|c|c|c|}
\hline Author, Year & $\begin{array}{l}\text { Gender/Species/Weight } \\
\text { (gr) }\end{array}$ & Model/Location of injury/Severity & $\begin{array}{l}\text { Cell source/Donor/Graft/Dose/Type/Intervention time } \\
\text { (day) }\end{array}$ & $\begin{array}{l}\text { Immunosuppressive/ } \\
\text { Antibiotic/Blinding }\end{array}$ & $\begin{array}{l}\text { Follow up } \\
\text { (week) }\end{array}$ \\
\hline Macias et al., 2006 & Female/Rat/200-250 & Contusion/T8/Moderate & Brain/Newborn/Mice/IS/1 × 105/Xenogeneic/8 & Yes/Yes/Yes & 4 \\
\hline Nemati et al., 2014 & $\begin{array}{l}\text { Male/monkeys/3000- } \\
6000\end{array}$ & Contusion/T9-T10/Moderate & Brain/Adult/Monkey/IS/3-6 × 106/Allogeneic/10 & Yes/Yes/Yes & 26 \\
\hline Nishimura et al., 2013 & Female/Mice/18-22 & Contusion/T10/Moderate & Brain/Fetus/Mice/IS/5 $\times 105 /$ Allogeneic/9 or 42 & No/No/Yes & 6 \\
\hline Nori et al., 2011 & Female/mice/20-22 & Contusion/T10/Moderate & Skin fibroblast/Adult/Human/IS/5 × 105/Xenogeneic/9 & No/No/Yes & 7 \\
\hline Nutt et al., 2013 & Female/Rat/180-230 & Contusion/C4/Moderate & Lung/Adult/Human/IS/2 × 105/Xenogeneic/28 & Yes/No/Yes & 8 \\
\hline Okada et al., 2005 & Female/Mice/20-22 & Contusion/T10/Moderate & Brain/Fetus/Mice/IS/5 $\times 105 /$ Allogeneic/ 1 or 7 & $\mathrm{No} / \mathrm{No} / \mathrm{No}$ & 6 \\
\hline Ormond et al., 2014 & Female/Rat/200-250 & $\begin{array}{l}\text { Contusion/T9-T10/Moderate or } \\
\text { Severe }\end{array}$ & Brain/Adult/Rat/IS/1 × 106/Allogeneic/7 & No/No/Yes & 5 \\
\hline Pallini et al., 2005 & Female/Mice/27-30 & Transection/T7-T8/Severe & Brain/Fetus/Mice/IS/1 × 105/Allogeneic/1 & $\mathrm{No} / \mathrm{No} / \mathrm{No}$ & 12 \\
\hline Pan et al., 2008 & Female/Rat/250-300 & Transection/T8-T9/Severe & Brain/Fetus/Rat/IS/5 × 106/Allogeneic/1 & No/Yes/Yes & 12 \\
\hline Park et al., 2013 & Female/Rat/250-300 & Contusion/T10/Moderate & Brain/Fetus/Human/IS/5 × 105/Xenogeneic/7 & $\mathrm{No} / \mathrm{No} / \mathrm{Yes}$ & 6 \\
\hline Parr et al., 2008a & Female/Rat/250-300 & Compression/T8-T9/Moderate & Brain/Adult/Rat/IS/2 $\times 105$ or $1.25 \times 105 /$ Allogeneic/ 9 & Yes/No/Yes & 14 \\
\hline Parr et al., 2008b & Female/Rat/250-300 & Compression/T8-T9/Moderate & Brain/Adult/Rat/IS/2 $\times 105$ or $1.25 \times 105 /$ Allogeneic/ 9 & Yes/No/Yes & 12 \\
\hline Parr et al., 2007 & Female/Rat/250-300 & Compression/T8-T9/Moderate & Spine/Adult/Rat/IS/1 × 105/Allogeneic/1 & Yes/No/Yes & 16 \\
\hline Piltti et al., 2013a & Female/Rat/180-200 & Contusion/T9/Severe & Brain/Fetus/Human/IS/2 × 105/Xenogeneic/9 & Yes/Yes/Yes & 13 \\
\hline Piltti et al., 2013b & Female/Rat/180-200 & Contusion/T9/Severe & Brain/Fetus/Human/IS/2 × 105/Xenogeneic/9 & Yes/Yes/Yes & 13 \\
\hline Pomeshchik et al., 2015 & Female/Mice/18-23 & Contusion/T10/Moderate & Skin/Adult/Human/IS/4 × 105/Xenogeneic/7 & Yes/No/Yes & 5 \\
\hline Romanyuk et al., 2015 & Male/Rat/270-300 & $\begin{array}{l}\text { Balloon compression/T8-T9/ } \\
\text { Moderate }\end{array}$ & Lung/Fetus/Human/IS/5 × 105/Xenogeneic/7 & Yes/Yes/Yes & 8 \\
\hline Salazar et al., 2010 & Female/Mice/15-20 & Contusion/T9/Moderate & Brain/Fetus/Human/IS/7.5 × 104/Xenogeneic/30 & No/Yes/Yes & 16 \\
\hline Salewski et al., 2015a & Female/Mice/15-20 & Compression/T6-T8/Moderate & Brain/Fetus/Human/IS/2 × 105/Allogeneic/7 & Yes/No/Yes & 8 \\
\hline Salewski et al., 2015b & Female/Mice/15-20 & Compression/T6-T8/Moderate & $\begin{array}{l}\text { Embryonic fibroblast/Fetus/Human/IS/2 × 105/ } \\
\text { Allogeneic/7 }\end{array}$ & Yes/No/Yes & 8 \\
\hline Sharp et al., 2014 & Female/Rat/145-160 & Transection/T3/Severe & Brain/Fetus/Rat/IS/1.5 × 106/Allogeneic/14 & No/Yes/Yes & 7 \\
\hline Sontag et al., 2013 & Female/m/20-25 & Contusion/T9/Moderate & Brain/Fetus/Human/IS/7.5 × 105/Xenogeneic/9 & Yes/No/Yes & 10 \\
\hline Tarasenko et al., 2007 & Male/Rat/230-340 & Contusion/T10/Moderate & Brain/Fetus/Human/IS/1 × 105/Xenogeneic/9 & Yes/Yes/Yes & 12 \\
\hline Teng et al., 2002 & Female/Rat/280-330 & Hemisection/T9-T10/Severe & Brain/Newborn/Murine/IS/1 × 105/Xenogeneic/1 & No/No/Yes & 10 \\
\hline Tsuji et al., 2010 & Female/Mice/20-22 & Contusion/T10/Moderate & Embryonic stem cell/Fetus/Mice/IS/5 × 105/Allogeneic/9 & No/No/Yes & 5 \\
\hline van Gorp et al., 2013 & Female/Rat/200-250 & Compression/L3/Moderate & Spine/Fetus/Human/IS/1.2 × 105/Xenogeneic/3 & Yes/Yes/Yes & 8 \\
\hline Wang et al., 2014 & Female/Rat/220-250 & Transection/T10/Severe & Brain/Fetus/Rat/IS/1 × 106/Allogeneic/1 & No/Yes/Yes & 4 \\
\hline Wang et al., 2011 & Female/Rat/220-250 & Transection/T10/Severe & Brain/newborn/Rat/IS/1 × 106/Allogeneic/1 & No/Yes/Yes & 8 \\
\hline Xia et al., 2013 & Female/Rat/200-300 & Hemisection/T8/Severe & Spine/Fetus/Rat/IS/5 × 105/Allogeneic/1 & No/Yes/Yes & 24 \\
\hline Xu et al., 2011 & Female/Rat/200 & Contusion/T9/Moderate & Brain/Fetus/Rat/IS/5 × 105/Allogeneic/56 & No/Yes/Yes & 8 \\
\hline Yamane et al., 2010 & $\begin{array}{l}\text { Female/Marmoset/280- } \\
350\end{array}$ & Contusion/C5/Moderate & Brain/Fetus/Human/IS/1 × 106/Xenogeneic/9 & Yes/Yes/Yes & 12 \\
\hline Yang et al., 2013 & Male/Rat/300-350 & Contusion/T9-T10/Moderate & Brain/Fetus/Porcine/IS/1 × 105/Xenogeneic/7 & $\mathrm{No} / \mathrm{No} / \mathrm{No}$ & 24 \\
\hline Yao et al., 2015 & Male/Rat/200-220 & Transection/T10/Severe & Brain/Fetus/Mice/IS/3 × 106/Xenogeneic/1 & No/Yes/No & 5 \\
\hline Yasuda et al., 2011 & Female/Mice/20-22 & Contusion/T10/Moderate & Brain/Fetus/Mice/IS/5 × 105/Allogeneic/9 & No/No/Yes & 6 \\
\hline Yokota et al., 2015 & Female/Mice/20-22 & Contusion/T8/Moderate or Severe & Brain/Fetus/Mice/IS/5 × 105/Allogeneic/9 & No/No/No & 6 \\
\hline Yuan et al., 2014 & Female/Rat/250-300 & Hemisection/T9-T10/Severe & Brain/Newborn/Mice/IS/1 × 107/Allogeneic/1 & $\mathrm{No} / \mathrm{No} / \mathrm{No}$ & 4 \\
\hline Zhang et al., 2007 & Female/Rat/200-250 & Transection/T10/Severe & Brain/Newborn/Rat/IS/1 × 106/Allogeneic/1 & No/Yes/No & 8 \\
\hline Ziv et al., 2006 & Female/Mice/20-22 & Contusion/T12/Severe & Brain/Fetus/Mice/ICV/5 × 105/Allogeneic/7 & No/No/Yes & 4 \\
\hline
\end{tabular}

IS: intra-spinal; IT: intrathecal; ICV: intra cerebroventricular; T: thoracic level of spinal cord; C: cervical level spinal cord; L: lumbar level of spinal cord. 
118 experiments had evaluated the efficacy of NSPC transplantation on functional recovery of subjects after SCl (Cummings et al., 2005; Iwanami et al., 2005; Okada et al., 2005; Pallini et al., 2005; Ziv et al., 2006; Guo et al., 2007, 2012; Parr et al., 2007, 2008a,b; Tarasenko et al., 2007; Zhang et al., 2007; Bottai et al., 2008; Lowry et al., 2008; Pan et al., 2008; Hooshmand et al., 2009; Kumagai et al., 2009; Lee et al., 2009; Abematsu et al., 2010; Chen et al., 2010; Johnson et al., 2010; Tsuji et al., 2010; Yamane et al., 2010; Du et al., 2011; Kim et al., 2011, 2012; Nori et al., 2011; Wang et al., 2011, 2014; Xu et al., 2011; Yasuda et al., 2011; Cheng et al., 2012; Cusimano et al., 2012; Fujimoto et al., 2012; Gu et al., 2012; Kobayashi et al., 2012; Lu et al., 2012, 2014; Amemori et al., 2013, 2015; He et al., 2013; Kumamaru et al., 2013; Nishimura et al., 2013; Nutt et al., 2013; Park et al., 2013; Xia et al., 2013; Yang et al., 2013; Hong et al., 2014; Hwang et al., 2014; Iwasaki et al., 2014; Nemati et al., 2014; Ormond et al., 2014; Sharp et al., 2014; Yuan et al., 2014; Iwai et al., 2015; Liu et al., 2015; Pomeshchik et al., 2015; Romanyuk et al., 2015; Yokota et al., 2015; Salewski et al., 2015a). Findings of this section are presented in Fig. 2. Transplantation of these cells significantly improved restoration of motor function in the subjects (Pooled SMD $=1.45 ;$ 95\% Cl: 1.23-1.67; $\left.p<0.001 ; \quad l^{2}=81.0 \%\right)$. Publication bias was not observed in this part of the study (Coefficient $=1.30$; $95 \% \mathrm{Cl}:-0.49$ to $3.09 ; p=0.15)$. Due to a considerable heterogeneity $\left(I^{2}=81.1 \% ; p<0.001\right)$, subgroup analysis was performed. According to the findings presented in Table 3, injury model, intervention phase, transplanted cells numbers, and immunosuppressive administration were found to be the main sources of heterogeneity. Cell efficacy considerably dropped (SMD $=0.58 ; 95 \% \mathrm{Cl}$ : 0.16-0.99) when cells were used in clip compression induced SCls model compared to transection $(\mathrm{SMD}=2.18 ; 95 \% \mathrm{Cl}: 1.45-2.93)$ model. Moreover, this treatment improved motor function recovery to a greater extent when cells were transplanted in acute $(\mathrm{SMD}=1.80 ; \quad 95 \% \quad \mathrm{Cl}: 1.36-2.24)$ or sub-acute $(\mathrm{SMD}=1.38 ; 95 \% \mathrm{Cl}: 1.08-1.67)$ phases compared to the chronic phase $(\mathrm{SMD}=1.04 ; 95 \% \mathrm{Cl}$ : $0.47-1.60)$ $(p=0.03)$. Findings also showed better functional recovery where more than $3 \times 10^{6}$ cell dose $/ \mathrm{kg}$ was transplanted $(\mathrm{SMD}=1.74 ; 95 \% \mathrm{Cl}: 1.43-2.05)$ compared lower doses injection (SMD $=0.94 ; 95 \% \mathrm{Cl}$ : 0.67-1.22). Immunosuppressive administration provoked significantly lower efficacies (SMD $=0.87 ; 95 \% \mathrm{Cl}$ : 0.57-1.17).

In addition, co-treatment with growth factors (SMD $=0.93 ; 95 \% \mathrm{Cl}:-0.22$ to 2.08 ) and Schwann cells or bone marrow-derived mesenchymal cells $(\mathrm{SMD}=1.21 ; 95 \% \mathrm{Cl}:-0.24$ to 2.65$)$ hindered neural stem cells effects, while scaffold application $(\mathrm{SMD}=2.19 ; \quad 95 \% \mathrm{Cl}:$ 1.30-2.07) improved cells efficacy. Motor function recovery was also found to be lower when cells were transplanted in cervical injuries $(\mathrm{SMD}=0.54 ; 95 \% \mathrm{Cl}: 0.05-1.03)$ compared to thoracic injuries (SMD $=1.52 ; 95 \% \mathrm{Cl}: 1.28-1.75)$. Finally, wildtype NSPC transplantation (SMD $=1.41 ; 95 \% \mathrm{Cl}: 1.18-$ 1.64) and induced pluripotent stem cell-derived (iPSc- derived) NSPC (SMD $=1.64 ; 95 \% \mathrm{Cl}$ : 0.83-2.45) had similar effects on motor function recovery.

Efficacy of neural stem cell transplantation on sensory status. Allodynia. Nine studies (Hofstetter et al., 2005; Macias et al., 2006; Hu et al., 2010; KarimiAbdolrezaee et al., 2010; Salazar et al., 2010; Piltti et al., 2013a,b; Sontag et al., 2013; Salewski et al., 2015b) including 11 experiments evaluated NSPCs efficacy on allodynia among the subjects (Fig. 3). NSPC transplantation had no significant effect on allodynia (Pooled SMD $=0.08$; 95\% Cl: -0.33 to $0.49 ; p=0.69$; $I^{2}=58.4 \%$ ). Study heterogeneity persuaded us to conduct subgroup analysis in this section as well. Since in all these surveys female mice were also included and intrathoracic spinal transplantation was performed, these factors were excluded from the subgroup analyses. As presented in Table 4, none of the evaluated factors significantly influenced NSPCs efficacy on allodynia.

Hyperalgesia. Eleven surveys (Teng et al., 2002; Hofstetter et al., 2005; Macias et al., 2006; KarimiAbdolrezaee et al., 2010; Luo et al., 2013; Piltti et al., 2013a,b; van Gorp et al., 2013; Amemori et al., 2015; Salewski et al., 2015b; Yao et al., 2015) including 16 experiments examined NSPC efficacy of on hyperalgesia (Fig. 3). Pooled analysis demonstrated that NSPC transplantation had no significant effect on hyperalgesia (Pooled SMD $=0.25 ; 95 \% \mathrm{Cl}:-0.10$ to $0.60 ; p=0.16$; $P^{2}=64.4 \%$ ). However, subgroup analysis showed improved hyperalgesia to some extent when NSPCs were extracted from mice (SMD $=0.33 ; 95 \% \mathrm{Cl}$ : 0.02-0.67) rather than rats $(\mathrm{SMD}=-0.18 ; 95 \% \mathrm{Cl}:-0.56$ to 0.21$)$ or human $(\mathrm{SMD}=0.37 ; 95 \% \mathrm{Cl}$ : -0.48 to 1.17$)$. Transplantation of more than $3 \times 10^{6}$ cell dose $/ \mathrm{kg}$ $(\mathrm{SMD}=0.37 ; 95 \% \mathrm{Cl}:-0.02$ to 0.77$)$ in the first day after injury induction $(\mathrm{SMD}=0.33 ; 95 \% \mathrm{Cl}$ : -0.02 to 0.24 ) slightly improved hyperalgesia as well. Findings are presented in Table 5.

\section{DISCUSSION}

The present study, for the first time, designed to review the data gathered from animal models evaluating of NSPC transplantation efficacy on functional recovery and neuropathic pain relief in $\mathrm{SCl}$ through a quantitative approach. Findings confirmed that NSPC transplantation could significantly improve motor function recovery in the studied animals. NSPC efficacy was affected by the injury model (compression, contusion, hemisection, and transection), intervention phase, transplanted cell number, and immunosuppressive administration. Scaffold use with transplanted NSPCs could also boost transplantation efficacy. In addition, mice-derived NSPCs were found to be considerably more effective for hyperalgesia alleviation than rat or human origin cells. Transplanted cell numbers and intervention phase were also reported to affect hyperalgesia improvement. Allodynia, on the other hand, was not affected by NSPC transplantation.

Reviews, on the other hand, have been reported improvement in NSPC implantation efficacy on motor 
Table 2. Quality assessment of included studies

\begin{tabular}{|c|c|c|c|c|c|c|c|c|c|c|c|c|c|c|c|c|c|c|c|}
\hline Author, year & 1 & 2 & 3 & 4 & 5 & 6 & 7 & 8 & 9 & 10 & 11 & 12 & 13 & 14 & 15 & 16 & 17 & 18 & 19 \\
\hline Abematsu et al., 2010 & $\nu$ & & $r$ & $\nu$ & $\boldsymbol{r}$ & $\nu$ & & $\nu$ & $\nu$ & $\nu$ & & $\nu$ & $\nu$ & $\nu$ & $r$ & $r$ & $\nu$ & $\nu$ & $\nu$ \\
\hline Amemori et al., 2013 & レ & & $\boldsymbol{V}$ & $\boldsymbol{\nu}$ & レ & 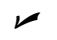 & & $\boldsymbol{v}$ & レ & レ & & $\nu$ & $\swarrow$ & レ & & $\boldsymbol{}$ & $\boldsymbol{\nu}$ & 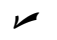 & 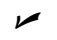 \\
\hline Amemori et al., 2015 & $\boldsymbol{V}$ & & $\boldsymbol{V}$ & レ & レ & 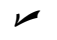 & & $\boldsymbol{V}$ & レ & レ & & レ & レ & レ & & $\boldsymbol{V}$ & レ & $\boldsymbol{V}$ & 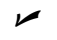 \\
\hline Bottai et al., 2008 & $\boldsymbol{}$ & $\boldsymbol{\nu}$ & $\boldsymbol{}$ & $\boldsymbol{\nu}$ & $\boldsymbol{}$ & レ & & $\boldsymbol{v}$ & レ & $\boldsymbol{}$ & & 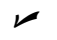 & レ & & & $\boldsymbol{}$ & $\boldsymbol{}$ & 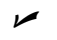 & \\
\hline Chen et al., 2010 & $\boldsymbol{\nu}$ & $\boldsymbol{\nu}$ & $\boldsymbol{V}$ & $\boldsymbol{\nu}$ & $レ$ & 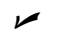 & & レ & レ & レ & 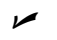 & 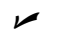 & $\swarrow$ & 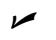 & & $\boldsymbol{}$ & $\boldsymbol{\nu}$ & 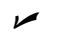 & \\
\hline Cheng et al., 2012 & $\boldsymbol{}$ & & $\boldsymbol{}$ & レ & レ & 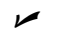 & $\boldsymbol{}$ & $\boldsymbol{v}$ & レ & レ & & $レ$ & レ & $\boldsymbol{\nu}$ & & $\boldsymbol{}$ & レ & $\boldsymbol{}$ & \\
\hline Cummings et al., 2005 & & & $\boldsymbol{V}$ & $\boldsymbol{\nu}$ & レ & 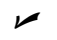 & & $\boldsymbol{V}$ & レ & レ & 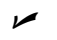 & 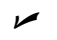 & $\swarrow$ & & $\boldsymbol{}$ & $\boldsymbol{V}$ & $\boldsymbol{\nu}$ & & \\
\hline Cusimano et al., 2012 & $\boldsymbol{}$ & & レ & レ & $\boldsymbol{V}$ & 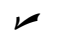 & & r & レ & $\boldsymbol{V}$ & & $\boldsymbol{}$ & レ & 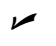 & & レ & $\boldsymbol{V}$ & $\boldsymbol{V}$ & \\
\hline Du et al., 2011 & レ & & レ & レ & レ & 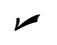 & & レ & レ & レ & $\boldsymbol{\nu}$ & $レ$ & レ & $\boldsymbol{V}$ & & $\boldsymbol{}$ & レ & $レ$ & \\
\hline Fujimoto et al., 2012 & $\nu$ & & $r$ & $\nu$ & $\boldsymbol{r}$ & $\nu$ & & $\nu$ & レ & $\nu$ & & $\nu$ & $\nu$ & $\nu$ & & $r$ & $\nu$ & $\nu$ & $\nu$ \\
\hline Gu et al., 2012 & レ & & $\boldsymbol{}$ & レ & $\boldsymbol{}$ & 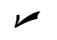 & & $\boldsymbol{v}$ & レ & $\boldsymbol{V}$ & & $レ$ & レ & & & $\boldsymbol{}$ & & 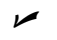 & \\
\hline Guo et al., 2007 & $\boldsymbol{\nu}$ & & レ & $\boldsymbol{\nu}$ & $レ$ & 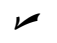 & & 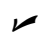 & レ & レ & & $\nu$ & $\nu$ & $\nu$ & & $\boldsymbol{r}$ & & $\nu$ & \\
\hline Guo et al., 2012 & レ & & レ & $\boldsymbol{V}$ & $\boldsymbol{}$ & 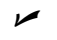 & & $\boldsymbol{v}$ & $\boldsymbol{\nu}$ & レ & & & レ & レ & & $\boldsymbol{V}$ & レ & $\boldsymbol{V}$ & レ \\
\hline He et al., 2013 & $\boldsymbol{\nu}$ & & $\boldsymbol{V}$ & $\boldsymbol{\nu}$ & $レ$ & 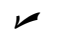 & & レ & レ & レ & & $\nu$ & $\swarrow$ & & & $\boldsymbol{}$ & $\boldsymbol{\nu}$ & $\nu$ & \\
\hline Hofstetter et al., 2005 & レ & & $\nu$ & $\nu$ & レ & $\nu$ & & v & レ & レ & $\nu$ & $\nu$ & 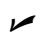 & & & レ & 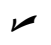 & $\nu$ & $\nu$ \\
\hline Hong et al., 2014 & $\nu$ & $r$ & $\nu$ & $\nu$ & $\nu$ & $\nu$ & & $\nu$ & $\nu$ & レ & & $\nu$ & $\nu$ & $\nu$ & & 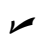 & $\nu$ & $\nu$ & \\
\hline Hooshmand et al., 2009 & $\boldsymbol{}$ & $\boldsymbol{V}$ & レ & レ & $\boldsymbol{V}$ & 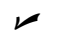 & & r & レ & $\boldsymbol{V}$ & $v$ & $\boldsymbol{}$ & レ & 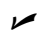 & レ & レ & $\boldsymbol{V}$ & $\boldsymbol{V}$ & 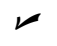 \\
\hline Hu et al., 2010 & レ & & レ & レ & レ & 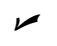 & & & レ & レ & & & レ & & & レ & & 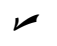 & 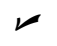 \\
\hline Hwang et al., 2014 & & & レ & $\boldsymbol{\nu}$ & レ & $\nu$ & & $\nu$ & $\nu$ & レ & $\nu$ & $\nu$ & $レ$ & $\nu$ & & $\boldsymbol{r}$ & レ & $\nu$ & \\
\hline Iwai et al., 2015 & レ & $\boldsymbol{V}$ & $\boldsymbol{\nu}$ & レ & レ & $\boldsymbol{}$ & & $\boldsymbol{V}$ & レ & レ & & $\boldsymbol{}$ & レ & レ & & $\boldsymbol{V}$ & & $\boldsymbol{V}$ & 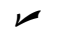 \\
\hline Iwanami et al., 2005 & レ & レ & $\boldsymbol{V}$ & $\boldsymbol{V}$ & レ & $\boldsymbol{V}$ & & $\boldsymbol{V}$ & $\boldsymbol{V}$ & レ & & $\boldsymbol{V}$ & レ & レ & & $\boldsymbol{V}$ & & $\boldsymbol{V}$ & \\
\hline Iwasaki et al., 2014 & $\boldsymbol{V}$ & $\boldsymbol{V}$ & $\boldsymbol{\nu}$ & レ & $\boldsymbol{}$ & 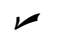 & & $\boldsymbol{v}$ & $\boldsymbol{V}$ & レ & $\boldsymbol{\nu}$ & $\boldsymbol{V}$ & レ & レ & & $\boldsymbol{}$ & レ & $\boldsymbol{v}$ & 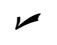 \\
\hline Johnson et al., 2010 & $\boldsymbol{}$ & & $\boldsymbol{\nu}$ & $\boldsymbol{\nu}$ & $\boldsymbol{}$ & 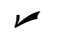 & & $\boldsymbol{v}$ & レ & レ & & $レ$ & レ & $\boldsymbol{\nu}$ & & $\boldsymbol{}$ & $\boldsymbol{\nu}$ & $\boldsymbol{}$ & \\
\hline Karimi-Abdolrezaee et al., 2010 & $\boldsymbol{\nu}$ & $\boldsymbol{r}$ & $\nu$ & $\nu$ & $\boldsymbol{}$ & 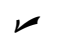 & & レ & レ & レ & 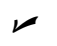 & $\nu$ & $\nu$ & 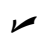 & & $\boldsymbol{r}$ & $\boldsymbol{\nu}$ & $\nu$ & \\
\hline Karimi-Abdolrezaee et al., 2 & $\nu$ & $\boldsymbol{\nu}$ & $\nu$ & $\nu$ & $\boldsymbol{V}$ & $\nu$ & & $\nu$ & レ & $\nu$ & $\nu$ & $\nu$ & $\nu$ & $\nu$ & $\nu$ & 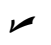 & $\nu$ & $\nu$ & \\
\hline Kim & $\boldsymbol{\nu}$ & & $\boldsymbol{\nu}$ & $\boldsymbol{\nu}$ & レ & 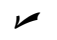 & & レ & $\boldsymbol{\nu}$ & レ & & $\nu$ & $\nu$ & & & $\boldsymbol{r}$ & & $\nu$ & $\nu$ \\
\hline 2012 & $\boldsymbol{V}$ & & レ & レ & レ & 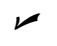 & & $\boldsymbol{r}$ & レ & レ & & 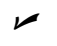 & レ & & & $\boldsymbol{V}$ & $\boldsymbol{V}$ & $\boldsymbol{V}$ & 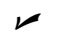 \\
\hline Kobayashi, 2012 & レ & $\boldsymbol{V}$ & $\boldsymbol{\nu}$ & レ & $\boldsymbol{V}$ & 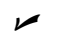 & & レ & レ & レ & & $レ$ & レ & レ & & レ & & $レ$ & 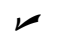 \\
\hline Kumagai et al., 2009 & $\nu$ & & $\nu$ & $\nu$ & $\boldsymbol{r}$ & 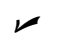 & & r & レ & レ & & $\nu$ & $\nu$ & & & $\boldsymbol{r}$ & $\nu$ & $\nu$ & $\nu$ \\
\hline Kumamaru et al., 2013 & レ & $\boldsymbol{V}$ & $\boldsymbol{\nu}$ & $\boldsymbol{\nu}$ & レ & 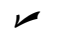 & & $\boldsymbol{v}$ & レ & $\boldsymbol{V}$ & & $レ$ & レ & & & $\boldsymbol{}$ & $\nu$ & 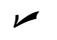 & 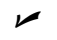 \\
\hline Lee et al., 2009 & 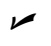 & $\boldsymbol{V}$ & $\nu$ & レ & レ & 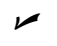 & & $r$ & レ & $\boldsymbol{V}$ & & $v$ & $\boldsymbol{V}$ & $v$ & & レ & & $v$ & \\
\hline Liu et al., 2015 & $\boldsymbol{\nu}$ & & $\nu$ & $\boldsymbol{\nu}$ & $\boldsymbol{}$ & 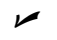 & & $v$ & レ & $\boldsymbol{V}$ & & 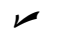 & レ & $\boldsymbol{V}$ & & $\boldsymbol{}$ & $\boldsymbol{\nu}$ & 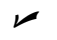 & $\nu$ \\
\hline tal., 2008 & レ & & $\nu$ & $\nu$ & 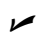 & $\nu$ & & $\nu$ & $\nu$ & $\nu$ & & $\nu$ & $\nu$ & & & 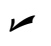 & $\nu$ & $\nu$ & $\nu$ \\
\hline Lu e & $\nu$ & & $\nu$ & $\nu$ & $\nu$ & $\nu$ & & $\nu$ & $\nu$ & $\nu$ & & $\nu$ & $\nu$ & & & $r$ & $\nu$ & $\nu$ & $\nu$ \\
\hline Lu $€$ & レ & & $\nu$ & レ & レ & $\nu$ & & $v$ & レ & レ & & $レ$ & $レ$ & & & $\boldsymbol{r}$ & レ & $レ$ & $\nu$ \\
\hline Luo & レ & & レ & レ & 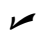 & $\nu$ & & 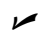 & レ & V & & $\nu$ & レ & レ & & レ & $\nu$ & $v$ & $\nu$ \\
\hline Macias et al., 2006 & $\boldsymbol{V}$ & & レ & レ & 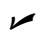 & V & & $\boldsymbol{v}$ & レ & レ & $\nu$ & $\boldsymbol{V}$ & レ & レ & レ & $\boldsymbol{}$ & レ & $\boldsymbol{v}$ & \\
\hline Nemati et al., 2014 & レ & & $\nu$ & 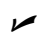 & レ & $\nu$ & & $\nu$ & $\nu$ & $\nu$ & $\nu$ & $\nu$ & 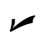 & 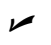 & & レ & $\nu$ & $レ$ & レ \\
\hline Nishimura et al., 2013 & レ & & $\boldsymbol{\nu}$ & $\boldsymbol{\nu}$ & 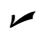 & 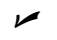 & & $\boldsymbol{v}$ & レ & $\boldsymbol{V}$ & & $レ$ & レ & & & $\boldsymbol{}$ & $\boldsymbol{\nu}$ & 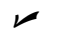 & $\boldsymbol{}$ \\
\hline Nori et al., 2011 & $\boldsymbol{V}$ & & $\boldsymbol{V}$ & レ & レ & 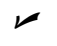 & & $\boldsymbol{V}$ & $\boldsymbol{V}$ & レ & & 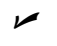 & レ & & $\boldsymbol{V}$ & $\boldsymbol{V}$ & $\boldsymbol{V}$ & $\nu$ & $\nu$ \\
\hline Nutt et al., 2013 & $\boldsymbol{V}$ & & $\boldsymbol{V}$ & レ & レ & V & & $\boldsymbol{v}$ & レ & レ & & $\boldsymbol{V}$ & レ & & & $\boldsymbol{}$ & レ & $v$ & \\
\hline Okada et al., 2005 & レ & & $\boldsymbol{\nu}$ & レ & $\boldsymbol{}$ & 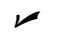 & & $\boldsymbol{v}$ & レ & $\boldsymbol{V}$ & & $レ$ & レ & & & $\boldsymbol{}$ & & 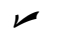 & \\
\hline al., 2014 & レ & $\boldsymbol{r}$ & $\nu$ & レ & レ & $\nu$ & & 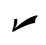 & $\nu$ & 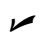 & $\nu$ & $\nu$ & $レ$ & & レ & レ & $\nu$ & $\nu$ & $\nu$ \\
\hline Pallin & レ & $\boldsymbol{V}$ & $\nu$ & $\nu$ & $\boldsymbol{r}$ & $\nu$ & & $v$ & レ & レ & & $レ$ & レ & $\boldsymbol{r}$ & & $\boldsymbol{V}$ & & $レ$ & \\
\hline 2008 & $\boldsymbol{\nu}$ & & $\boldsymbol{\nu}$ & $\boldsymbol{\nu}$ & $レ$ & 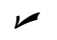 & & レ & レ & レ & & $\nu$ & $\swarrow$ & $\boldsymbol{V}$ & & $\boldsymbol{}$ & $\boldsymbol{\nu}$ & $\nu$ & \\
\hline Park et al., 2013 & レ & & $\nu$ & レ & 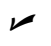 & 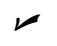 & $\nu$ & $\boldsymbol{v}$ & レ & レ & 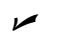 & $レ$ & 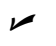 & & & $\boldsymbol{}$ & レ & 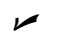 & \\
\hline Parr et al., 2008a & レ & & レ & レ & レ & 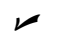 & & v & レ & レ & & $レ$ & $レ$ & & $レ$ & レ & レ & $\nu$ & \\
\hline Parr et al., 2008b & $\nu$ & & $\nu$ & $\nu$ & $\boldsymbol{r}$ & $\nu$ & & r & レ & $\nu$ & & $\nu$ & $\nu$ & & & $r$ & $\nu$ & $\nu$ & \\
\hline Parr et al., 2007 & $\boldsymbol{V}$ & & $\boldsymbol{r}$ & レ & レ & 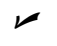 & & $\boldsymbol{V}$ & $\boldsymbol{V}$ & レ & & 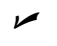 & レ & & & $\boldsymbol{V}$ & $\boldsymbol{V}$ & $\nu$ & \\
\hline al., 2013a & レ & & $\boldsymbol{r}$ & $\boldsymbol{V}$ & $\boldsymbol{V}$ & 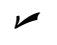 & & レ & レ & レ & 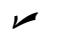 & $\nu$ & レ & $\boldsymbol{V}$ & $\boldsymbol{r}$ & $\boldsymbol{V}$ & $\boldsymbol{V}$ & $\nu$ & 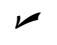 \\
\hline., $2013 b$ & $\boldsymbol{}$ & & $\boldsymbol{r}$ & $\boldsymbol{\nu}$ & $\boldsymbol{}$ & 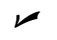 & & $\boldsymbol{v}$ & レ & $\boldsymbol{V}$ & 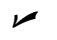 & $レ$ & レ & $\boldsymbol{}$ & $\boldsymbol{r}$ & $\boldsymbol{}$ & $\boldsymbol{\nu}$ & 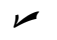 & 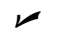 \\
\hline Pomeshchik et al., 20 & レ & $\boldsymbol{\nu}$ & $\boldsymbol{r}$ & 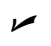 & レ & 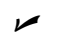 & & レ & レ & レ & $\nu$ & $\nu$ & 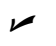 & レ & $\boldsymbol{r}$ & $\boldsymbol{r}$ & レ & $\nu$ & 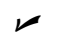 \\
\hline Romanyuk et al., 2015 & レ & & $\boldsymbol{r}$ & レ & $\boldsymbol{}$ & 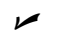 & & $\boldsymbol{v}$ & $\boldsymbol{V}$ & レ & & レ & レ & レ & $\boldsymbol{r}$ & $\boldsymbol{}$ & レ & $v$ & $\nu$ \\
\hline Salaz & $\boldsymbol{V}$ & レ & $\boldsymbol{r}$ & $\boldsymbol{V}$ & レ & $\boldsymbol{V}$ & & レ & レ & レ & 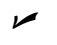 & $\nu$ & レ & $\boldsymbol{V}$ & $\boldsymbol{r}$ & $\boldsymbol{V}$ & $\boldsymbol{V}$ & $\nu$ & 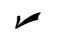 \\
\hline Salewski et al., 2015a & $\boldsymbol{}$ & $\boldsymbol{V}$ & $\boldsymbol{r}$ & $\boldsymbol{}$ & レ & 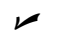 & & $\boldsymbol{r}$ & レ & レ & 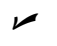 & $\boldsymbol{V}$ & $\boldsymbol{V}$ & 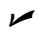 & & 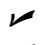 & レ & $\nu$ & 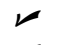 \\
\hline Salewski et al., $2015 \mathrm{~b}$ & レ & & $\boldsymbol{r}$ & レ & レ & 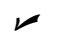 & & $\boldsymbol{v}$ & レ & レ & 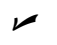 & $レ$ & $レ$ & & & $\boldsymbol{V}$ & レ & 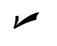 & $\nu$ \\
\hline Sharp et al., 2014 & レ & $\boldsymbol{v}$ & $\boldsymbol{r}$ & レ & レ & 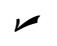 & & レ & $\boldsymbol{\nu}$ & レ & $\nu$ & $\nu$ & $\nu$ & $\boldsymbol{r}$ & $\boldsymbol{r}$ & $\boldsymbol{r}$ & レ & $\nu$ & \\
\hline Sontag et al., 2013 & レ & & $\boldsymbol{r}$ & レ & レ & 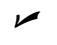 & & レ & レ & レ & レ & 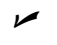 & レ & & レ & 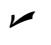 & レ & 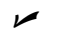 & 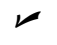 \\
\hline Tarasenko et al., 2007 & $\boldsymbol{V}$ & & $\boldsymbol{r}$ & レ & レ & 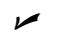 & & $\boldsymbol{r}$ & レ & レ & $v$ & 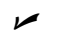 & $\boldsymbol{V}$ & レ & & $\boldsymbol{V}$ & レ & $\boldsymbol{V}$ & \\
\hline Teng et al., 2002 & $\boldsymbol{V}$ & & $\boldsymbol{r}$ & レ & $\boldsymbol{V}$ & $\boldsymbol{V}$ & & $\boldsymbol{v}$ & レ & レ & レ & $\boldsymbol{V}$ & レ & $\boldsymbol{V}$ & $\boldsymbol{r}$ & $\boldsymbol{}$ & レ & $\boldsymbol{V}$ & \\
\hline Tsuji et al., 2010 & レ & & $\boldsymbol{r}$ & $\boldsymbol{V}$ & レ & $\boldsymbol{V}$ & & レ & レ & レ & & $\nu$ & レ & & & $\boldsymbol{V}$ & & $\nu$ & 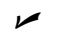 \\
\hline van Gorp et al., 2013 & レ & $\boldsymbol{r}$ & $\boldsymbol{r}$ & レ & $\boldsymbol{V}$ & $\nu$ & & $\nu$ & レ & $\nu$ & $\nu$ & $\nu$ & レ & $\boldsymbol{r}$ & $\boldsymbol{r}$ & レ & $\boldsymbol{\nu}$ & $\nu$ & $\nu$ \\
\hline Wang et al., 2014 & レ & & $\boldsymbol{r}$ & レ & レ & 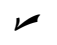 & & $\boldsymbol{v}$ & レ & レ & $\boldsymbol{\nu}$ & $レ$ & レ & $\boldsymbol{}$ & & $v$ & $\nu$ & $v$ & $\nu$ \\
\hline
\end{tabular}


Table 2 (continued)

\begin{tabular}{|c|c|c|c|c|c|c|c|c|c|c|c|c|c|c|c|c|c|c|c|}
\hline Author, year & 1 & 2 & 3 & 4 & 5 & 6 & 7 & 8 & 9 & 10 & 11 & 12 & 13 & 14 & 15 & 16 & 17 & 18 & 19 \\
\hline Wang et al., 2011 & $r$ & $r$ & $\nu$ & 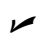 & $r$ & $\nu$ & & $\nu$ & $\nu$ & $\nu$ & & $\nu$ & $r$ & $\nu$ & & $\nu$ & $\nu$ & $r$ & $\nu$ \\
\hline Xia et al., 2013 & $\boldsymbol{r}$ & $r$ & $\nu$ & $\nu$ & $r$ & $\nu$ & & $\nu$ & レ & レ & $\nu$ & $\nu$ & $r$ & $\nu$ & & $\boldsymbol{\nu}$ & レ & $\boldsymbol{\nu}$ & $\nu$ \\
\hline Xu et al., 2011 & $\boldsymbol{r}$ & $\boldsymbol{r}$ & $\boldsymbol{\nu}$ & $\boldsymbol{\nu}$ & $\boldsymbol{r}$ & レ & & $\nu$ & レ & $\boldsymbol{V}$ & 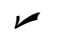 & $\swarrow$ & $\boldsymbol{r}$ & $\nu$ & $\nu$ & $\boldsymbol{V}$ & 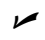 & $\boldsymbol{r}$ & \\
\hline Yamane et al., 2010 & $\boldsymbol{\nu}$ & & $\boldsymbol{\nu}$ & $\boldsymbol{\nu}$ & $\boldsymbol{r}$ & $\boldsymbol{}$ & & $\boldsymbol{}$ & $\boldsymbol{\nu}$ & $\boldsymbol{\nu}$ & & レ & $\boldsymbol{r}$ & レ & レ & $\boldsymbol{\nu}$ & & $\boldsymbol{\nu}$ & \\
\hline Yang et al., 2013 & $\boldsymbol{r}$ & & $\boldsymbol{\nu}$ & $\boldsymbol{\nu}$ & $\boldsymbol{r}$ & 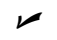 & & $\nu$ & レ & $\boldsymbol{V}$ & 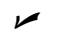 & $\swarrow$ & $\boldsymbol{r}$ & $\nu$ & レ & $\boldsymbol{\nu}$ & & $\boldsymbol{r}$ & $\nu$ \\
\hline Yao et al., 2015 & $r$ & & $\boldsymbol{\nu}$ & $\boldsymbol{\nu}$ & $r$ & レ & & $\nu$ & $\nu$ & v & $\nu$ & レ & $r$ & $\nu$ & & レ & $\nu$ & $r$ & $r$ \\
\hline Yasuda, 2011 & $\boldsymbol{r}$ & $\boldsymbol{r}$ & $\boldsymbol{\nu}$ & $\boldsymbol{\nu}$ & $\boldsymbol{r}$ & レ & & $\nu$ & レ & $\boldsymbol{V}$ & & $\swarrow$ & $\boldsymbol{r}$ & $\nu$ & & $\boldsymbol{\nu}$ & $\nu$ & $\boldsymbol{r}$ & $r$ \\
\hline Yokota et al., 2015 & $r$ & & $\boldsymbol{\nu}$ & $\nu$ & $r$ & $\nu$ & & $\nu$ & レ & v & & $\nu$ & $r$ & & & $\boldsymbol{\nu}$ & & $r$ & $r$ \\
\hline Yuan et al., 2014 & $\boldsymbol{r}$ & $r$ & $\boldsymbol{\nu}$ & レ & $r$ & レ & & $\nu$ & $\boldsymbol{V}$ & $\boldsymbol{V}$ & 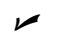 & $レ$ & $r$ & $レ$ & & レ & & $\boldsymbol{r}$ & $r$ \\
\hline Zhang et al., 2007 & $r$ & & レ & $r$ & $\boldsymbol{r}$ & レ & & $\nu$ & $\nu$ & $\nu$ & $\nu$ & $\swarrow$ & $r$ & $\nu$ & & レ & & $r$ & \\
\hline Ziv et al., 2006 & $\boldsymbol{r}$ & & $\nu$ & $r$ & $r$ & v & & $\nu$ & $\boldsymbol{\nu}$ & $\nu$ & & $\nu$ & $r$ & & & $\nu$ & $\boldsymbol{\nu}$ & $r$ & r \\
\hline
\end{tabular}

1. Compliance with animal welfare regulations; 2 . Statement describing control of temperature; 3 . Publication in a peer-reviewed journal; 4 . Description of anima; species; 5 . Designation of strain; 6 . Number of animals per group; 7 . Sample size calculation; 8 . Present of animals' age/weight; 9 . Description of level of Injury; 10 . Severity of Injury 11. Randomly assigning animals to a specific group; 12. Allocation concealment 13. Description of the control groups; 14. Bladder expression; 15 . Description of the reasons to exclude animals from the experiment during the study (attrition); 16. Use of appropriate tests to prove hypothesis; 17 . Blindness of assessor; 18 . Description of statistical analysis; 19 . Statement of any potential conflict of interest.

function recovery too. For instance, Tetzlaff et al. also reported that most surveys have verified the positive effects of NSPC transplantation on motor function outcomes of the evaluated animals. However, they did not find the optimal source of NSPCs for this purpose (Tetzlaff et al., 2011). In this regard, we performed subgroup analysis based on donor species and NSPC embryonic or adult source. No significant differences were observed between embryonic and adult NSPC effects on motor function recovery, or neuropathic pain relief. Mothe and Tator found relative improvements of motor function recovery in response to NSPC transplantation (Mothe and Tator, 2013).

Although, NSPCs are suitable sources for $\mathrm{SCl}$ alleviation, ethical issues on fetal human origin tissues and lack of autologous cell sources have limited their uses (Mothe and Tator, 2013). Therefore, adult tissuederived NSPCs may be used for SCI treatment. In recent years, alternative sources were introduced for NSPC derivation. IPSC-derived NSPCs originated from reprogramed somatic cells provide an autologous source for NSPCs without ethical concerns. In spite of experimental studies with improved motor function recovery post iPSCderived NSPC transplantation in SCl cases, some studies depicted no significant effect. The present meta-analysis showed that both wild-type and iPSC-derived NSPCs could drastically improve motor function recovery. Previous studies demonstrated that iPSC-derived NSPCs provide therapeutic benefits via the same mechanisms as wild-type or embryonic stem cell-derived NPSCs (Lu et al., 2012). Transplantation of iPSC-derived NSPCs could improve myelin repair, axon regeneration, and neurotropic factors secretion while reduced secondary inflammatory responses, (Nori et al., 2011; Fujimoto et al., 2012; Nutt et al., 2013; Romanyuk et al., 2015). Therefore, similar efficacy of the two mentioned sources of stem cells in motor function recovery was not unexpected. Including seven studies in their systematic review, LeeKubli and Lu demonstrated promising survival, differentiation and therapeutic effect of iPSC-derived NSPC transplantation after $\mathrm{SCl}$. However, they stated that ideal iPSC reprograming and differentiation remain unclear and need further investigation (Lee-Kubli and Lu, 2015). Our results have reached to the conclusion as Lee-Kubli and Lu study.

We included 12 studies in which iPSC-derived NSPCs provoked a great efficacy differences in motor function recovery (Tsuji et al., 2010; Nori et al., 2011; Fujimoto et al., 2012; Nutt et al., 2013; Hong et al., 2014; Lu et al., 2014; Amemori et al., 2015; Liu et al., 2015; Pomeshchik et al., 2015; Romanyuk et al., 2015; Salewski et al., 2015b). One plausible reason for such heterogeneity may be rooted in the age of somatic cell donor (embryonic or adult). Therefore, we performed more specific analyses, based on the iPSC embryonic or adult somatic source. In this context, results showed that efficacy of embryonic-derived iPSCs (SMD = 1.89; 95\% Cl: 0.93-2.84) was considerably higher than those with adult somatic source $(\mathrm{SMD}=0.79 ; 95 \% \mathrm{Cl}$ : $0.32-$ 1.25). The difference may be due to adult somatic tissue-derived iPSCs characteristics i.e., the cells displayed significant resistance to differentiation (Tsuji et al., 2011). Mothe and Tator, stated that adult human NSPCs were difficult to expand for sufficient cell transplantation. They also added that iPSCs could trigger Tcell induced immune response in syngeneic recipients (Mothe and Tator, 2013). Moreover, adult tissue-derived iPSCs were not as safe as embryonic-derived clones which, could form teratoma in $\mathrm{SCl}$ implantation (Tsuji et al., 2011). However, our current knowledge regarding iPSC-derived NSPC tumorigenicity, safety, and alternative reprograming is still insufficient.

Motor function recovery post NSPC transplantation is generally affected by intervention phase. Findings revealed that a shorter time gap between injury induction and transplantation could improve the efficiency of the treatment. Accordingly, transplantation during acute and sub-acute phases is associated with better results compared to chronic phase. This might be due to the partial irreversible nature of the injuries in chronic phase (Oyinbo, 2011). Similar efficacy of the acute and sub-acute phases has been the notable finding among the studies. This is incongruent with the current assumption, since acute phase inflammatory responses 


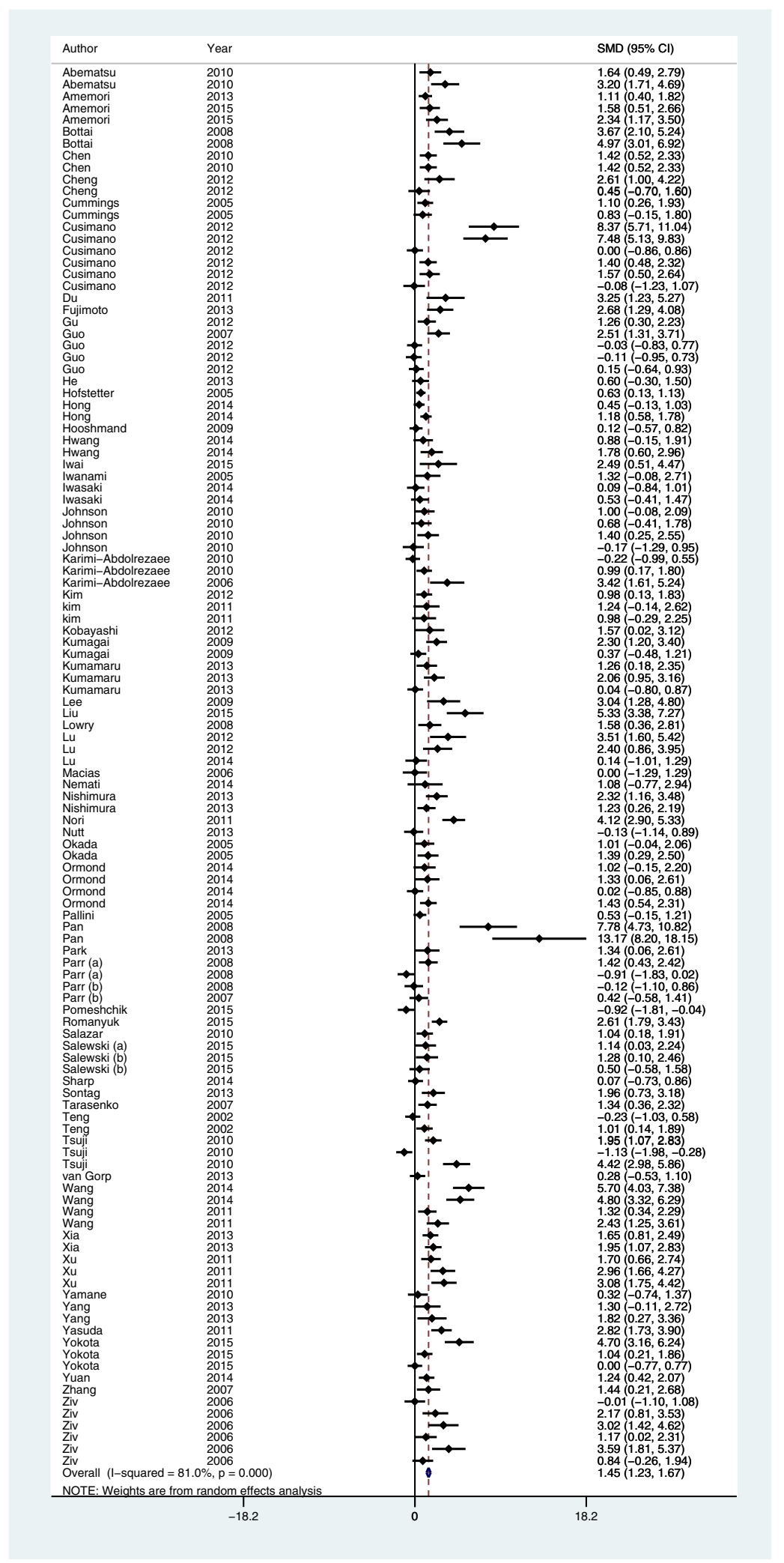

Fig. 2. Efficacy of neural stem/progenitor cells transplantation on motor function recovery after spinal cord injury. This method significantly improved functional recovery.

creates a cytotoxic environment, which is incompatible with the NSPC survival and differentiation and focuses on better results of the cell therapy in sub-acute phase than acute and chronic phases (Mothe and Tator, 2013). The present study showed that treatment in the acute phase had even slightly higher efficacy than sub- 
Table 3. Subgroup analyses of the effect of neural stem/progenitor cells on functional recovery

\begin{tabular}{|c|c|c|c|c|c|}
\hline Characteristic & $P$ for bias ${ }^{a}$ & Model & $P\left(I^{2}\right)^{\mathrm{b}}$ & Effect size ${ }^{c}(95 \% \mathrm{Cl})$ & $P$ \\
\hline \multicolumn{6}{|l|}{ Gender } \\
\hline Male & 0.93 & REM & $<0.001(80.3 \%)$ & $1.91(1.37-2.45)$ & $<0.001$ \\
\hline \multirow[t]{2}{*}{ Female } & 0.43 & REM & $<0.001(80.9 \%)$ & $1.35(1.10-1.56)$ & $<0.001$ \\
\hline & & & \multicolumn{2}{|c|}{ Overall significance test among subgroups } & 0.14 \\
\hline \multicolumn{6}{|l|}{ Recipient species } \\
\hline Mice & 0.05 & REM & $<0.001(85.1 \%)$ & $1.68(1.27-2.09)$ & $<0.001$ \\
\hline Rat & 0.17 & REM & $<0.001(78.9 \%)$ & $1.30(1.03-1.58)$ & $<0.001$ \\
\hline \multirow[t]{2}{*}{ Other } & 0.45 & FEM & $0.12(42.3 \%)$ & $1.48(0.64-2.31)$ & $<0.001$ \\
\hline & & & \multicolumn{2}{|c|}{ Overall significance test among subgroups } & 0.42 \\
\hline \multicolumn{6}{|l|}{ Injury model } \\
\hline Contusion & 0.92 & REM & $<0.001(81.7 \%)$ & $1.54(1.23-1.86)$ & $<0.001$ \\
\hline Clip compression & 0.44 & REM & $0.001(61.4 \%)$ & $0.58(0.16-0.99)$ & 0.007 \\
\hline Balloon compression & 0.31 & REM & $0.04(63.9 \%)$ & $1.88(1.11-2.64)$ & $<0.001$ \\
\hline Hemisection & 0.49 & REM & $0.004(57.4 \%)$ & $1.10(0.69-1.51)$ & $<0.001$ \\
\hline \multirow{2}{*}{ Transection } & 0.44 & REM & $<0.001(88.1 \%)$ & $2.18(1.45-2.93)$ & $<0.001$ \\
\hline & & & \multicolumn{2}{|c|}{ Overall significance test among subgroups } & 0.045 \\
\hline \multicolumn{6}{|l|}{ Location of injury } \\
\hline Cervical & 0.13 & FEM & $0.20(28.3 \%)$ & $0.54(0.05-1.03)$ & 0.03 \\
\hline Thoracic & 0.52 & REM & $<0.001(81.9 \%)$ & $1.52(1.28-1.75)$ & $<0.001$ \\
\hline \multirow[t]{2}{*}{ Lumbar } & NA & NA & NA & NA & NA \\
\hline & & & \multicolumn{2}{|c|}{ Overall significance test among subgroups } & 0.054 \\
\hline \multicolumn{6}{|l|}{ Severity of injury } \\
\hline Mild & NA & NA & NA & NA & NA \\
\hline Moderate & 0.61 & REM & $<0.001(80.0 \%)$ & $1.28(0.99-1.57)$ & $<0.001$ \\
\hline \multirow[t]{2}{*}{ Severe } & 0.59 & REM & $<0.001(82.5 \%)$ & $1.70(1.33-2.06)$ & $<0.001$ \\
\hline & & & \multicolumn{2}{|c|}{ Overall significance test among subgroups } & 0.17 \\
\hline \multicolumn{6}{|c|}{ Stem cells derivation origin } \\
\hline Brain & 0.65 & REM & $<0.001(81.7 \%)$ & $1.50(1.24-1.77)$ & $<0.001$ \\
\hline Spine & 0.06 & REM & $<0.001(71.1 \%)$ & $1.51(1.03-1.98)$ & $<0.001$ \\
\hline \multirow[t]{2}{*}{ Other } & 0.81 & REM & $<0.001(89.6 \%)$ & $1.64(0.83-2.45)$ & $<0.001$ \\
\hline & & & Overall significan & mong subgroups & 0.39 \\
\hline Cell type & & & & & \\
\hline wt-NSPCs & 0.74 & REM & $<0.001(78.5 \%)$ & $1.41(1.18-1.64)$ & $<0.001$ \\
\hline iPSC-NSPCs & 0.81 & REM & $<0.001(89.6 \%)$ & $1.64(0.83-2.45)$ & $<0.001$ \\
\hline & & & Overall significan & mong subgroups & 0.75 \\
\hline Intervention phase ${ }^{\mathrm{d}}$ & & & & & \\
\hline Acute & 0.20 & REM & $<0.001(82.8 \%)$ & $1.80(1.36-2.24)$ & $<0.001$ \\
\hline Subacute & 0.79 & REM & $<0.001(83.2 \%)$ & $1.38(1.08-1.67)$ & $<0.001$ \\
\hline Chronic & 0.90 & REM & $<0.001(75.1 \%)$ & $1.04(0.47-1.60)$ & $<0.001$ \\
\hline & & & Overall significan & mong subgroups & 0.044 \\
\hline Delivery route & & & & & \\
\hline Intra spinal & 0.65 & REM & $<0.001(81.5 \%)$ & $1.42(1.19-1.66)$ & $<0.001$ \\
\hline Other & 0.92 & REM & $<0.001(74.9 \%)$ & $1.88(1.04-2.71)$ & $<0.001$ \\
\hline & & & Overall significan & mong subgroups & 0.43 \\
\hline Graft type & & & & & \\
\hline Allogeneic & 0.35 & REM & $<0.001(83.3 \%)$ & $1.66(1.35-1.97)$ & $<0.001$ \\
\hline Xenogeneic & 0.02 & REM & $<0.001(75.1 \%)$ & $1.13(0.81-1.44)$ & $<0.001$ \\
\hline & & & Overall significan & mong subgroups & 0.10 \\
\hline Number of transplantec & & & & & \\
\hline$<3 \times 10^{6}$ cell dose $/ \mathrm{kg}$ & 0.92 & REM & $<0.001(64.5 \%)$ & $0.94(0.67-1.22)$ & $<0.001$ \\
\hline$\geqslant 3 \times 10^{6}$ cell dose $/ \mathrm{kg}$ & 0.13 & REM & $<0.001(84.3 \%)$ & $1.74(1.43-2.05)$ & $<0.001$ \\
\hline & & ‘ & Overall significan & mong subgroups & 0.02 \\
\hline Donor species & & & & & \\
\hline Mice & 0.54 & REM & $<0.001(83.1 \%)$ & $1.48(1.13-1.83)$ & $<0.001$ \\
\hline Rat & 0.06 & REM & $<0.001(83.3 \%)$ & $1.53(1.10-1.97)$ & $<0.001$ \\
\hline Human & 0.39 & REM & $<0.001(76.5 \%)$ & $1.33(0.89-1.76)$ & $<0.001$ \\
\hline Other & 0.73 & FEM & $0.72(0.0 \%)$ & $1.61(0.79-2.44)$ & $<0.001$ \\
\hline
\end{tabular}


Table 3 (continued)

\begin{tabular}{|c|c|c|c|c|c|}
\hline Characteristic & $P$ for bias ${ }^{a}$ & Model & $P\left(I^{2}\right)^{\mathrm{b}}$ & Effect size ${ }^{\mathrm{c}}(95 \% \mathrm{Cl})$ & $P$ \\
\hline \multicolumn{6}{|l|}{ Donor age } \\
\hline Fetal & 0.37 & REM & $<0.001(78.7 \%)$ & $1.60(1.33-1.87)$ & $<0.001$ \\
\hline Newborn & $>0.99$ & REM & $<0.001(71.8 \%)$ & $1.32(0.64-2.00)$ & $<0.001$ \\
\hline \multirow[t]{2}{*}{ Adult } & 0.90 & REM & $<0.001(84.3 \%)$ & $1.14(0.69-1.59)$ & $<0.001$ \\
\hline & & & \multicolumn{2}{|c|}{ Overall significance test among subgroups } & 0.20 \\
\hline \multicolumn{6}{|l|}{ Use of co-treatment } \\
\hline No & 0.99 & REM & $<0.001(81.2 \%)$ & $1.36(1.10-1.62)$ & $<0.001$ \\
\hline Scaffold & 0.84 & REM & $<0.001(82.2 \%)$ & $2.19(1.30-2.07)$ & $<0.001$ \\
\hline SC cells or BMMSC & 0.60 & REM & $<0.001(88.9 \%)$ & $1.21(-0.24$ to 2.65$)$ & 0.10 \\
\hline Growth factors & 0.12 & REM & $<0.001(85.6 \%)$ & $0.93(-0.22$ to 2.08$)$ & 0.11 \\
\hline \multirow[t]{2}{*}{ Other } & 0.002 & REM & $<0.001(78.9 \%)$ & $1.79(1.16-2.41)$ & $<0.001$ \\
\hline & & & \multicolumn{2}{|c|}{ Overall significance test among subgroups } & 0.72 \\
\hline \multicolumn{6}{|l|}{ Use of antibiotic } \\
\hline No & 0.17 & REM & $<0.001(77.9 \%)$ & $1.24(0.98-1.51)$ & $<0.001$ \\
\hline \multirow[t]{2}{*}{ Yes } & 0.56 & REM & $<0.001(84.0 \%)$ & $1.77(1.37-2.16)$ & $<0.001$ \\
\hline & & & \multicolumn{2}{|c|}{ Overall significance test among subgroups } & 0.11 \\
\hline \multicolumn{6}{|c|}{ Use of immunosuppressive agents } \\
\hline No & 0.94 & REM & $<0.001(82.7 \%)$ & $1.80(1.49-2.10)$ & $<0.001$ \\
\hline \multirow[t]{2}{*}{ Yes } & 0.49 & REM & $<0.001(72.4 \%)$ & $0.87(0.57-1.17)$ & $<0.001$ \\
\hline & & & \multicolumn{2}{|c|}{ Overall significance test among subgroups } & 0.003 \\
\hline \multicolumn{6}{|l|}{ Blinding of observer } \\
\hline No & 0.74 & REM & $<0.001(67.7 \%)$ & $1.34(0.85-1.84)$ & $<0.001$ \\
\hline \multirow[t]{2}{*}{ Yes } & 0.85 & REM & $<0.001(82.3 \%)$ & $1.48(1.23-1.73)$ & $<0.001$ \\
\hline & & & \multicolumn{2}{|c|}{ Overall significance test among subgroups } & 0.82 \\
\hline \multicolumn{6}{|l|}{ Follow up period } \\
\hline$<8$ weeks & 0.003 & REM & $<0.001(81.6 \%)$ & $1.49(1.14-1.84)$ & $<0.001$ \\
\hline \multirow[t]{2}{*}{$\geqslant 8$ weeks } & 0.69 & REM & $<0.001(80.9 \%)$ & $1.42(1.21-1.72)$ & $<0.001$ \\
\hline & & & \multicolumn{2}{|c|}{ Overall significance test among subgroups } & 0.96 \\
\hline
\end{tabular}

Subacut: 3-10 days after injury; Chronic: equal or more than 14 days. REM: random effect model; FEM: fixed effect, CI: confidence interval; NA: not applicable because of low number of included studies; wt-NSPCS: wild type neural stem/progenitor cells; iPSC-NSPCs: induced pluripotent stem cell-derived neural stem cells.

a Publication bias based on Begg's and Egger's test.

b Heterogeneity among studies.

c Standardized mean difference.

d Acute: immediately after injury.

acute phase. It seems that the early presence of neural stem cells at the lesion site post injury can slow down inflammatory processes and decrease neural deaths. Various studies have shown neural stem cell modulatory effects on inflammatory/immune responses (Lee et al., 2008a,b; Bacigaluppi et al., 2009; Ottoboni et al., 2015). This is also rather compatible with our previous metaanalysis in which we showed higher efficiencies of bone marrow derived mesenchymal cell transplantation in neuropathic pain relief after $\mathrm{SCl}$ if the procedure carries out during the first 4 days of injury (Hosseini et al., 2015).

In the present meta-analysis, we found that the NSPC transplantation efficacy varied based on the injury induction model i.e. clip compression efficacy has found to be lower than the transection model. Different inflammatory processes seem to be the plausible explanation for this observation. In the transection model, the inflammatory processes are not activated in the first $12 \mathrm{~h}$ post injury and the nervous tissue is still viable at the edges of the cut point (Kao and chang, 1977) and NSPC transplantation can suspend inflammatory activation at the time. Yet, cell seeding has also been done using a scaffold in most of these surveys. In the compression model however, the inflammatory processes are activated from the first or second hour post-injury and the function and survival of the transplanted cells should be affected accordingly. Despite rare complete transection injuries in human, compression and contusion injuries are more prevalent (Bunge et al., 1993). Therefore, caution should be taken if clinical trials with NSPCs are designed.

Due to major discrepancies, the optimum number of transplanted cells is still a matter of debate. Median number of the cells per kilograms of animal's body weight was $4.3 \times 10^{6}$ (interquartile range $=1.1 \times 10^{6}-$ $\left.2 \times 10^{7}\right)$. In the present study, the $3 \times 10^{6}$ cell dose $/ \mathrm{kg}$ cut-off point was chosen based on some clinical situations (Hosseini et al., 2015). Higher doses have shown to provoke better functional recovery (Hosseini et al., 2015). This could be due to NSPC survival chance at higher doses efficient connections in the injured tissue.

Surprisingly, immunosuppressive administration has shown to decrease the efficacy in transplanted NSPC functional recovery after $\mathrm{SCl} \quad(\mathrm{SMD}=0.79$ vs. 


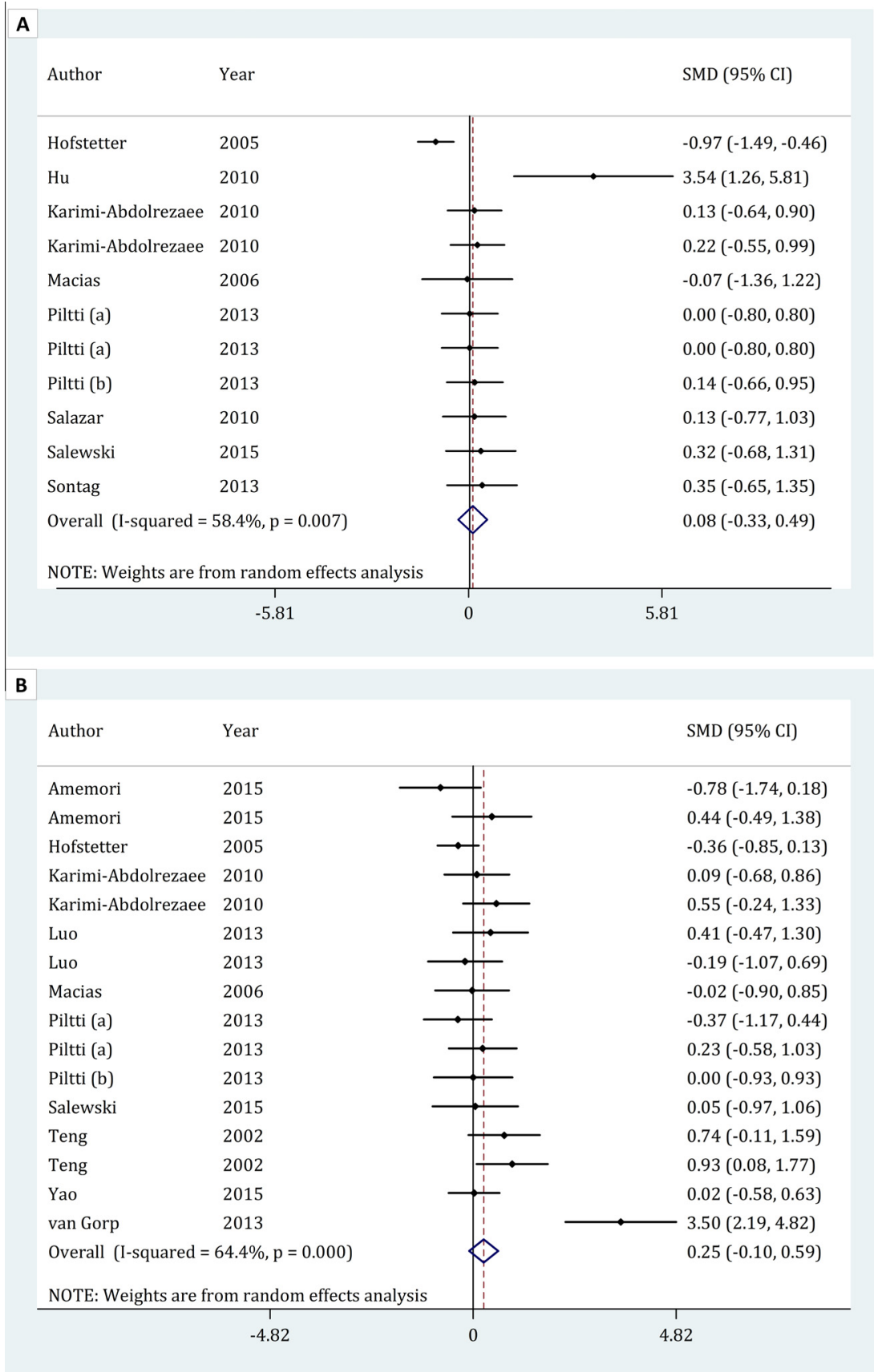

Fig. 3. Efficacy of neural stem/progenitor cells transplantation on allodynia (A) and hyperalgesia (B) after spinal cord injury. Neural stem/progenitor cells transplantation had no significant effect on allodynia and hyperalgesia.

SMD = 1.91). This is extremely difficult to rationalize. Most in vivo and in vitro studies have shown inhibitory effects of immunosuppressive medications on transplantation rejection and its facilitative influence on cell survival. Moreover, these agents can decrease inflammatory responses activated by traumatic spinal injury and increases growth and axon branching speed at the lesion site (Madsen et al., 1998; Xu et al., 1998). Immunosuppressive drug inhibitory effects on functional recovery might be due to their negative effects on wound and spinal cord healing (Park et al., 2013). However, we did not observe significant association between immunosuppressive use and efficacy of bone marrow derived stem cell transplantation with neuropathic pain relief after SCl (Hosseini et al., 2015). These findings are indicative of the need for further investigations on this matter.

The role of NSPC transplantation in neuropathic pain relief was another subject of this study. Analyses showed that NSPC transplantation could relieve hyperalgesia without any effect on allodynia. Eaton in his study showed that neural cell lines could alleviate neuropathic pains (Eaton, 2004). He only included those surveys with genetically engineered cell lines capable of 
Table 4. Subgroup analyses of the effect of neural stem/progenitor cells on allodynia

\begin{tabular}{|c|c|c|c|c|c|}
\hline Characteristic & $P$ for bias ${ }^{a}$ & Model & $P\left(I^{2}\right)^{\mathrm{b}}$ & Effect Size ${ }^{c}(95 \% \mathrm{Cl})$ & $P$ \\
\hline \multicolumn{6}{|l|}{ Recipient species } \\
\hline Mice & 0.50 & FEM & $0.07(48.6 \%)$ & $0.65(-0.27$ to 1.57$)$ & 0.16 \\
\hline \multirow[t]{2}{*}{ Rat } & 0.55 & FEM & $0.05(60.9 \%)$ & $-0.13(-0.54$ to 0.28$)$ & 0.53 \\
\hline & & & \multicolumn{2}{|c|}{ Overall significance test among subgroups } & 0.18 \\
\hline \multicolumn{6}{|l|}{ Injury model } \\
\hline Contusion & 0.91 & REM & $0.003(68.1 \%)$ & $0.08(-0.49$ to 0.64$)$ & 0.80 \\
\hline \multirow[t]{2}{*}{ Compression } & 0.12 & FEM & $0.96(0.0 \%)$ & $-0.27(-0.21$ ti 0.69$)$ & 0.39 \\
\hline & & & \multicolumn{2}{|c|}{ Overall significance test among subgroups } & 0.55 \\
\hline \multicolumn{6}{|l|}{ Severity of injury } \\
\hline Moderate & 0.46 & REM & $0.001(70.2 \%)$ & $0.16(-0.43$ to 0.76$)$ & 0.60 \\
\hline \multirow[t]{2}{*}{ Severe } & 0.30 & FEM & $0.96(0.0 \%)$ & $0.05(-0.41$ to 0.51$)$ & 0.84 \\
\hline & & & \multicolumn{2}{|c|}{ Overall significance test among subgroups } & 0.96 \\
\hline \multicolumn{6}{|c|}{ Stem cells derivation origin } \\
\hline Brain & 0.72 & FEM & $0.12(36.5 \%)$ & $-0.13(-0.38$ to 0.12$)$ & 0.31 \\
\hline \multirow[t]{2}{*}{ Other } & NA & NA & NA & NA & NA \\
\hline & & & \multicolumn{2}{|c|}{ Overall significance test among subgroups } & NA \\
\hline \multicolumn{6}{|l|}{ Intervention phase ${ }^{d}$} \\
\hline Acute & 0.11 & REM & $<0.001(93.1 \%)$ & $1.14(-3.27$ to 5.55$)$ & 0.62 \\
\hline Subacute & 0.37 & FEM & $0.99(0.0 \%)$ & $0.12(-0.25$ to 0.49$)$ & 0.49 \\
\hline \multirow[t]{2}{*}{ Chronic } & 0.60 & FEM & $0.98(0.0 \%)$ & $0.16(-0.30$ to 0.63$)$ & 0.54 \\
\hline & & & \multicolumn{2}{|c|}{ Overall significance test among subgroups } & 0.44 \\
\hline \multicolumn{6}{|l|}{ Graft type } \\
\hline Allogeneic & 0.60 & REM & $<0.001(88.8 \%)$ & $0.62(-1.22$ to 2.45$)$ & 0.51 \\
\hline \multirow[t]{2}{*}{ Xenogeneic } & 0.54 & FEM & $0.99(0.0 \%)$ & $0.12(-0.18$ to 0.42$)$ & 0.44 \\
\hline & & & \multicolumn{2}{|c|}{ Overall significance test among subgroups } & 0.46 \\
\hline Number of transplanteo & & & & & \\
\hline$<3 \times 10^{6}$ cell dose $/ \mathrm{kg}$ & 0.55 & REM & $0.07(48.6 \%)$ & $-0.13(-0.54$ to 0.28$)$ & 0.53 \\
\hline$\geqslant 3 \times 10^{6}$ cell dose $/ \mathrm{kg}$ & 0.50 & REM & $0.05(60.9 \%)$ & $0.65(-0.27$ to 1.57$)$ & 0.17 \\
\hline & & & Overall significanc & nong subgroups & 0.18 \\
\hline Donor species & & & & & \\
\hline Mice & 0.49 & REM & $0.01(64.0 \%)$ & $0.51(-0.40$ to 1.43$)$ & 0.27 \\
\hline Rat & NA & NA & NA & NA & NA \\
\hline Human & 0.38 & FEM & $0.99(0.0 \%)$ & $0.13(-0.22$ to 0.49$)$ & 0.46 \\
\hline & & & Overall significanc & nong subgroups & 0.79 \\
\hline Donor age & & & & & \\
\hline Fetal & 0.009 & FEM & $0.99(0.0 \%)$ & $0.13(-0.22$ to 0.49$)$ & 0.46 \\
\hline Newborn & NA & NA & NA & NA & NA \\
\hline Adult & 0.49 & REM & $<0.001(85.3 \%)$ & $-0.29(-0.82$ to 1.40$)$ & 0.69 \\
\hline & & & Overall significanc & nong subgroups & 0.38 \\
\hline Use of co-treatment & & & & & \\
\hline No & 0.46 & REM & $0.003(88.0 \%)$ & $0.09(-0.42$ to 0.60$)$ & 0.73 \\
\hline Yes & NA & NA & NA & NA & NA \\
\hline & & & Overall significanc & nong subgroups & 0.79 \\
\hline Use of antibiotic & & & & & \\
\hline No & 0.50 & REM & $<0.001(85.3 \%)$ & $0.46(-0.85$ to 1.76$)$ & 0.49 \\
\hline Yes & 0.55 & FEM & $0.99(0.0 \%)$ & $0.10(-0.22$ to 0.41$)$ & 0.56 \\
\hline & & & Overall significanc & nong subgroups & 0.22 \\
\hline Use of immunosuppres & & & & & \\
\hline No & 0.81 & REM & $<0.001(88.4 \%)$ & $0.50(-1.20$ to 2.2$)$ & 0.56 \\
\hline Yes & 0.34 & FEM & $0.99(0.0 \%)$ & $0.08(-0.33$ to 0.49$)$ & 0.38 \\
\hline & & & Overall significanc & nong subgroups & 0.32 \\
\hline Blinding of observer & & & & & \\
\hline No & NA & NA & NA & NA & NA \\
\hline Yes & 0.81 & FEM & $0.12(36.5 \%)$ & $-0.05(-0.38$ to 0.28$)$ & 0.78 \\
\hline & & & Overall significanc & nong subgroups & NA \\
\hline
\end{tabular}


Table 4 (continued)

\begin{tabular}{lllll}
\hline Characteristic & $P$ for bias $^{\mathrm{a}}$ & Model & $P\left(I^{2}\right)^{\mathrm{b}}$ & Effect Size $^{\mathrm{c}}(95 \% \mathrm{Cl})$ \\
\hline $\begin{array}{l}\text { Follow up period } \\
<8 \text { weeks }\end{array}$ & 0.50 & REM & $0.047(62.4 \%)$ & $0.56(-0.28$ to 1.39$)$ \\
$\geqslant 8$ weeks & 0.55 & REM & $0.08(47.3 \%)$ & $\begin{array}{l}-0.14(-0.57 \text { to } 0.29) \\
\text { Overall significance test among subgroups }\end{array}$ \\
\hline
\end{tabular}

Subacut: 3-10 days after injury; Chronic: equal or more than 14 days; REM: random effect model; FEM: fixed effect, Cl: confidence interval; NA: not applicable because of low number of included studies.

${ }^{a}$ Publication bias based on Begg's and Egger's test.

${ }^{b}$ Heterogeneity among studies.

${ }^{c}$ Standardized mean difference.

${ }^{d}$ Acute: immediately after injury.

Table 5. Subgroup analyses of the effect of neural stem/progenitor cells on hyperalgesia

\begin{tabular}{|c|c|c|c|c|c|}
\hline Characteristic & $P$ for bias ${ }^{a}$ & Model & $P\left(I^{2}\right)^{\mathrm{b}}$ & Effect Size ${ }^{c}(95 \% \mathrm{Cl})$ & $P$ \\
\hline \multicolumn{6}{|l|}{ Gender } \\
\hline Male & 0.30 & FEM & $0.19(39.8 \%)$ & $-0.05(-0.50$ to 0.40$)$ & 0.81 \\
\hline \multirow[t]{2}{*}{ Female } & 0.84 & REM & $<0.001(68.2 \%)$ & $0.34(-0.07$ to 0.75$)$ & 0.94 \\
\hline & & & \multicolumn{2}{|c|}{ Overall significance test among subgroups } & 0.44 \\
\hline \multicolumn{6}{|l|}{ Recipient species } \\
\hline Rat & 0.14 & REM & $<0.001(66.7 \%)$ & $0.26(-0.10$ to 0.63$)$ & 0.16 \\
\hline \multirow[t]{2}{*}{ Other } & NA & NA & NA & NA & NA \\
\hline & & & \multicolumn{2}{|c|}{ Overall significance test among subgroups } & NA \\
\hline \multicolumn{6}{|l|}{ Injury model } \\
\hline Contusion & 0.33 & FEM & $0.74(0.0 \%)$ & $-0.18(-0.50$ to 0.14$)$ & 0.29 \\
\hline Clip compression & 0.17 & REM & $<0.001(86.1 \%)$ & $0.96(-0.29$ to 2.22$)$ & 0.13 \\
\hline Balloon compression & NA & NA & NA & NA & NA \\
\hline Hemisection & NA & NA & NA & NA & NA \\
\hline \multirow[t]{2}{*}{ Transection } & 0.60 & REM & $<0.001(65.8 \%)$ & $0.06(-0.37$ to 0.50$)$ & 0.77 \\
\hline & & & \multicolumn{2}{|c|}{ Overall significance test among subgroups } & 0.64 \\
\hline \multicolumn{6}{|l|}{ Location of injury } \\
\hline Thoracic & 0.44 & FEM & $0.28(15.3 \%)$ & $0.07(-0.13$ to 0.27$)$ & 0.50 \\
\hline \multirow[t]{2}{*}{ Lumbar } & NA & NA & NA & NA & NA \\
\hline & & & \multicolumn{2}{|c|}{ Overall significance test among subgroups } & NA \\
\hline \multicolumn{6}{|l|}{ Severity of injury } \\
\hline Moderate & 0.18 & REM & $<0.001(83.5 \%)$ & $0.34(-0.32$ to 0.99$)$ & 0.31 \\
\hline \multirow[t]{2}{*}{ Severe } & 0.80 & FEM & $0.34(9.6 \%)$ & $0.20(-0.10$ to 0.50$)$ & 0.19 \\
\hline & & & \multicolumn{2}{|c|}{ Overall significance test among subgroups } & 0.84 \\
\hline \multicolumn{6}{|c|}{ Stem cells derivation origin } \\
\hline Brain & 0.54 & FEM & $0.38(6.9 \%)$ & $0.10(-0.12$ to 0.32$)$ & 0.12 \\
\hline Spine & NA & NA & NA & NA & NA \\
\hline \multirow[t]{2}{*}{ Lung } & NA & NA & NA & NA & NA \\
\hline & & & \multicolumn{2}{|c|}{ Overall significance test among subgroups } & NA \\
\hline \multicolumn{6}{|l|}{ Cell type } \\
\hline wt-NSPCs & 0.58 & REM & $<0.001(65.8 \%)$ & $0.30(-0.07$ to 0.67$)$ & 0.11 \\
\hline \multirow[t]{2}{*}{ ¡PSC-NSPCs } & NA & NA & NA & NA & NA \\
\hline & & & \multicolumn{2}{|c|}{ Overall significance test among subgroups } & NA \\
\hline \multicolumn{6}{|l|}{ Intervention phase ${ }^{\mathrm{d}}$} \\
\hline Acute & 0.99 & FEM & $0.27(22.6 \%)$ & $0.33(-0.02$ to 0.24$)$ & 0.07 \\
\hline Subacute & 0.99 & REM & $<0.001(76.3 \%)$ & $0.20(-0.38$ to 0.79$)$ & 0.38 \\
\hline \multirow[t]{2}{*}{ Chronic } & NA & NA & NA & NA & NA \\
\hline & & & \multicolumn{2}{|c|}{ Overall significance test among subgroups } & 0.89 \\
\hline \multicolumn{6}{|l|}{ Delivery route } \\
\hline Intra spinal & 0.32 & REM & $<0.001(66.4 \%)$ & $0.24(-0.12$ to 0.61$)$ & 0.20 \\
\hline Other & NA & NA & NA & NA & NA \\
\hline & & & Overall significanc & nong subgroups & NA \\
\hline
\end{tabular}


Table 5 (continued)

\begin{tabular}{|c|c|c|c|c|c|}
\hline Characteristic & $P$ for bias ${ }^{a}$ & Model & $P\left(I^{2}\right)^{\mathrm{b}}$ & Effect Size ${ }^{c}(95 \% \mathrm{Cl})$ & $P$ \\
\hline \multicolumn{6}{|l|}{ Graft type } \\
\hline Allogeneic & 0.25 & FEM & $0.50(0.0 \%)$ & $-0.15(-0.51$ to 0.21$)$ & 0.43 \\
\hline \multirow[t]{2}{*}{ Xenogeneic } & 0.73 & REM & $<0.001(69.3 \%)$ & $0.37(-0.08$ to 0.81$)$ & 0.10 \\
\hline & & & \multicolumn{2}{|c|}{ Overall significance test among subgroups } & 0.40 \\
\hline \multicolumn{6}{|c|}{ Number of transplanted cells } \\
\hline$<3 \times 10^{6}$ cell dose $/ \mathrm{kg}$ & 0.73 & REM & $<0.001(69.7 \%)$ & $0.20(-0.24$ to 0.64$)$ & 0.37 \\
\hline \multirow[t]{2}{*}{$\geqslant 3 \times 10^{6}$ cell dose $/ \mathrm{kg}$} & 0.16 & FEM & $0.26(25.5 \%)$ & $0.37(-0.02$ to 0.77$)$ & 0.06 \\
\hline & & & \multicolumn{2}{|c|}{ Overall significance test among subgroups } & 0.65 \\
\hline \multicolumn{6}{|l|}{ Donor species } \\
\hline Mice & 0.33 & FEM & $0.40(1.8 \%)$ & $0.33(0.02-0.65)$ & 0.04 \\
\hline Rat & 0.53 & FEM & $0.33(9.9 \%)$ & $-0.18(-0.56$ to 0.21$)$ & 0.36 \\
\hline \multirow[t]{2}{*}{ Human } & 0.99 & REM & $<0.001(80.4 \%)$ & $0.37(-0.48$ to 1.17$)$ & 0.28 \\
\hline & & & \multicolumn{2}{|c|}{ Overall significance test among subgroups } & 0.47 \\
\hline \multicolumn{6}{|l|}{ Donor age } \\
\hline Fetal & 0.33 & REM & $<0.001(81.3 \%)$ & $0.47(-0.35$ to 1.29$)$ & 0.26 \\
\hline Newborn & 0.19 & FEM & $0.27(22.9 \%)$ & $0.56(0.07-1.05)$ & 0.03 \\
\hline \multirow[t]{2}{*}{ Adult } & 0.30 & FEM & $0.22(27.5 \%)$ & $-0.04(-0.33$ to 0.25$)$ & 0.78 \\
\hline & & & \multicolumn{2}{|c|}{ Overall significance test among subgroups } & 0.43 \\
\hline \multicolumn{6}{|l|}{ Use of co-treatment } \\
\hline No & 0.21 & REM & $<0.001(74.0 \%)$ & $0.25(-0.20$ to 0.70$)$ & 0.28 \\
\hline \multirow[t]{2}{*}{ Yes } & 0.73 & FEM & $0.41(0.0 \%)$ & $0.30(-0.10$ to 0.71$)$ & 0.15 \\
\hline & & & \multicolumn{2}{|c|}{ Overall significance test among subgroups } & 0.90 \\
\hline \multicolumn{6}{|l|}{ Use of antibiotic } \\
\hline No & 0.42 & REM & $0.03(67.3 \%)$ & $0.29(-0.38$ to 0.97$)$ & 0.40 \\
\hline \multirow[t]{2}{*}{ Yes } & 0.16 & REM & $0.001(66.5 \%)$ & $0.25(-0.19$ to 0.67$)$ & 0.27 \\
\hline & & & \multicolumn{2}{|c|}{ Overall significance test among subgroups } & 0.72 \\
\hline \multicolumn{6}{|c|}{ Use of immunosuppressive agents } \\
\hline No & 0.53 & REM & $0.03(67.5 \%)$ & $0.25(-0.34$ to 0.85$)$ & 0.40 \\
\hline \multirow[t]{2}{*}{ Yes } & 0.21 & REM & $0.001(66.3 \%)$ & $0.25(-0.18$ to 0.70$)$ & 0.27 \\
\hline & & & \multicolumn{2}{|c|}{ Overall significance test among subgroups } & 0.97 \\
\hline \multicolumn{6}{|l|}{ Blinding of observer } \\
\hline No & NA & NA & NA & NA & NA \\
\hline \multirow[t]{2}{*}{ Yes } & 0.54 & REM & $<0.001(66.6 \%)$ & $0.27(-0.10$ to 0.65$)$ & 0.94 \\
\hline & & & \multicolumn{2}{|c|}{ Overall significance test among subgroups } & NA \\
\hline \multicolumn{6}{|l|}{ Follow up period } \\
\hline$>8$ weeks & 0.14 & FEM & $0.72(0.0 \%)$ & $0.16(-0.18$ to 0.51$)$ & 0.36 \\
\hline \multirow[t]{2}{*}{$\geqslant 8$ weeks } & 0.62 & REM & $<0.001(75.0 \%)$ & $0.32(-0.20$ to 0.83$)$ & 0.23 \\
\hline & & & \multicolumn{2}{|c|}{ Overall significance test among subgroups } & 0.30 \\
\hline
\end{tabular}

Subacut: 3-10 days after injury; Chronic: equal or more than 14 days. REM: random effect model; FEM: fixed effect, Cl: confidence interval; NA: not applicable because of low number of included studies; wt-NSPCS: wild type neural stem/progenitor cells; iPSC-NSPCs: induced pluripotent stem cell-derived neural stem cells.

a Publication bias based on Begg's and Egger's test.

b Heterogeneity among studies.

c Standardized mean difference.

d Acute: immediately after injury.

secreting potentially anti-nociceptive mediators, and immortalized cell lines used for neuropathic pain relief, rather than neural stem cells. Secretion of antinociceptive mediators such as met-enkephalin, gammaaminobutyric acid (GABA), and opioids can attenuate neuropathic pain symptoms. That would be the reason for the discrepant results of the two studies Furthermore, Franchi et al. in their narrative review referred to the neural stem cells as the suitable sources for neural regeneration and neuropathic pain relief (Franchi et al., 2014). In spite of our study that addresses central models, Franchi et al mainly focuses the chronic construction of the sci- atic nerve model with a peripheral aspect suitable for neural injuries induction. Referring to the different mechanisms of peripheral and central pain models (Burnett and Zager, 2004; Scholz and Woolf, 2007; Oyinbo, 2011), this controversy is predictable.

According to $\mathrm{Li}$ and Lepski neural stem cell transplantation has no significant effect on sensory status after SCls (Li and Lepski, 2013). This might be due to the neural stem cell high tendency for glial cell differentiation. Some studies have a differentiation rate of $40 \%$ to glial cells post transplantation compared with much less rate for neuronal differentiation (Tarasenko 
et al., 2007). These changes might exacerbate secondary injuries developed within the first hours post $\mathrm{SCl}$ and can persist through months or sometimes years after the insult (Rowland et al., 2008).

In our previous meta-analysis (Hosseini et al., 2015), we showed that bone marrow-derived mesenchymal stem cell implantation could improve allodynia with no significant effects on hyperalgesia unless it was implanted during the acute phase of injury. Mesenchymal stem cells could attenuate most unfavorable acute and chronic damages in the injured spinal cord (Wright et al., 2007; Teixeira et al., 2013). Implanted cells have a neuroprotective role (Uccelli et al., 2008) and can reduce proinflammatory cytokines, reactive oxygen species, and asteriogliosis (Abrams et al., 2009). These cells can also enhance host neural stem cell to oligodendrocytes differentiation and stimulate re-myelination (Rivera et al., 2006). However, NSPCs have less immunomodulatory properties and are apt to differentiate into astrocytes. Since NSPCs can develop some degree of allodynia and hyperalgesia in SCl animals (Hofstetter et al., 2005; Macias et al., 2006), their transplantation cannot significantly improve allodynia and hyperalgesia in the $\mathrm{SCl}$ animal models. According to Mothe and Tator, only predifferentiated NSPCs grafts in astrocytes can improve allodynia (Mothe and Tator, 2013).

Finally, subgroup analysis showed more improvements in hyperalgesia when NSPCs were extracted from mice rather than rats or human. Several reasons are required to explain this phenomenon. According to Mothe and Tator human derived NSPCs were either unavailable or difficult to grow (Mothe and Tator, 2013). In addition, Drukker and Benvenisty showed that human-derived NSPCs rejection imposed a great threat to their clinical use in regenerative medicine (Drukker and Benvenisty, 2004). In contrast, mouse NSPCs are a non-immunogenic immune-privileged tissue, and can be transplanted into allogeneic recipients without immunosuppressive regimens side effects (Hori et al., 2003).

\section{STRENGTHS AND LIMITATIONS}

In the present study, extended electronic search, authors contact, and manual webpage search were used to include maximum number of articles and gray literature. This method provided us with 74 studies and 125 experiments in the meta-analysis. Accordingly, data from 2382 animal subjects were pooled together and then analyzed. Absence of publication bias was one of the strengths of this survey. Heterogeneity in analyses was one of the study limitations, which was overcome through subgroup analysis. Lack of observers blinded to some included studies was another limitation. However, since in subgroup analysis neutrality is irrelevant to NSPCs transplantation efficacy on functional recovery and sensory condition, bias would accordingly be at its minimum levels.

\section{CONCLUSION}

Findings of the present meta-analysis showed that the efficacy of NSPC transplantation depends on the injury model, intervention phase, number of transplanted cells, immunosuppressive medications, and probably the cell source. The efficacy of this treatment method is higher in transection and contusion injury models than compression one. The shorter the interval between injury and treatment, led to the better the functional recovery and sensory condition. The best treatment dose was also found to be higher than $3 \times 10^{6}$ cell dose $/ \mathrm{kg}$. Immunosuppressive drug administration was found to negatively affect motor function recovery. Scaffold use could also boost NSPC efficacy on motor function recovery.

\section{AUTHOR CONTRIBUTIONS}

All authors passed four criteria for authorship contribution based on recommendations of the International Committee of Medical Journal Editors.

\section{CONFLICT OF INTEREST}

There are no conflicts of interest to report.

Acknowledgments-We kindly appreciate Dr. Hamid Sohanaki for his valuable help to language editing of the paper. This research has been supported by a Tehran University of Medical Sciences and Health Services grant (grant number: 94-02-3829291).

\section{REFERENCES}

Abematsu M, Tsujimura K, Yamano M, Saito M, Kohno K, Kohyama J, Namihira M, Komiya S, Nakashima K (2010) Neurons derived from transplanted neural stem cells restore disrupted neuronal circuitry in a mouse model of spinal cord injury. J Clin Investig 120:3255-3266.

Abrams MB, Dominguez C, Pernold K, Reger R, Wiesenfeld-Hallin Z, Olson L, Prockop D (2009) Multipotent mesenchymal stromal cells attenuate chronic inflammation and injury-induced sensitivity to mechanical stimuli in experimental spinal cord injury. Restorat Neurol Neurosci 27:307-321.

Amemori T, Romanyuk N, Jendelova P, Herynek V, Turnovcova K, Prochazka P, Kapcalova M, Cocks G, Price J, Sykova E (2013) Human conditionally immortalized neural stem cells improve locomotor function after spinal cord injury in the rat. Stem Cell Res Ther 4:68.

Amemori T, Ruzicka J, Romanyuk N, Jhanwar-Uniyal M, Sykova E, Jendelova P (2015) Comparison of intraspinal and intrathecal implantation of induced pluripotent stem cell-derived neural precursors for the treatment of spinal cord injury in rats. Stem Cell Res Ther 6:257.

Antonic A, Sena ES, Lees JS, Wills TE, Skeers P, Batchelor PE, Macleod MR, Howells DW (2013) Stem cell transplantation in traumatic spinal cord injury: a systematic review and metaanalysis of animal studies. PLoS Biol 11 e1001738.

Bacigaluppi M, Pluchino S, Jametti LP, Kilic E, Kilic Ü, Salani G, Brambilla E, West MJ, Comi G, Martino G (2009) Delayed postischaemic neuroprotection following systemic neural stem cell transplantation involves multiple mechanisms. Brain:awp174.

Backonja MM, Irving GA, Argoff C (2006) Rational multidrug therapy in the treatment of neuropathic pain. Curr Pain Headache Rep 10:34-38.

Bottai D, Madaschi L, Di Giulio AM, Gorio A (2008) Viabilitydependent promoting action of adult neural precursors in spinal cord injury. Mol Med (Cambridge, Mass) 14:634-644. 
Bunge RP, Puckett WR, Becerra JL, Marcillo A, Quencer RM (1993) Observations on the pathology of human spinal cord injury. A review and classification of 22 new cases with details from a case of chronic cord compression with extensive focal demyelination. Adv Neurol 59:75-89.

Burnett MG, Zager EL (2004) Pathophysiology of peripheral nerve injury: a brief review. Neurosurg Focus 16:1-7.

Chen G, Hu YR, Wan H, Xia L, Li JH, Yang F, Qu X, Wang SG, Wang ZC (2010) Functional recovery following traumatic spinal cord injury mediated by a unique polymer scaffold seeded with neural stem cells and Schwann cells. Chin Med J 123:2424-2431.

Cheng I, Mayle RE, Cox CA, Park DY, Smith RL, Corcoran-Schwartz I, Ponnusamy KE, Oshtory R, Smuck MW, Mitra R, Kharazi AI, Carragee EJ (2012) Functional assessment of the acute local and distal transplantation of human neural stem cells after spinal cord injury. Spine J 12:1040-1044.

Cummings BJ, Uchida N, Tamaki SJ, Salazar DL, Hooshmand M, Summers R, Gage FH, Anderson AJ (2005) Human neural stem cells differentiate and promote locomotor recovery in spinal cordinjured mice. Proc Natl Acad Sci USA 102:14069-14074.

Cusimano M, Biziato D, Brambilla E, Doneg M, Alfaro-Cervello C, Snider S, Salani G, Pucci F, Comi G, Garcia-Verdugo JM, De Palma M, Martino G, Pluchino S (2012) Transplanted neural stem/precursor cells instruct phagocytes and reduce secondary tissue damage in the injured spinal cord. Brain 135:447-460.

Drukker M, Benvenisty N (2004) The immunogenicity of human embryonic stem-derived cells. Trends Biotechnol 22:136-141.

Du BL, Xiong Y, Zeng CG, He LM, Zhang W, Quan DP, Wu JL, Li Y, Zeng YS (2011) Transplantation of artificial neural construct partly improved spinal tissue repair and functional recovery in rats with spinal cord transection. Brain Res 1400:87-98.

Eaton M (2004) Cell therapy for neuropathic pain in spinal cord injuries. Exp Opin Biol Ther 4:1861-1869.

Egger M, Smith GD, Schneider M, Minder C (1997) Bias in metaanalysis detected by a simple, graphical test. BMJ 315:629-634.

Finnerup NB (2013) Pain in patients with spinal cord injury. Pain 154: S71-S76.

Finnerup NB, Otto M, McQuay HJ (2005) Algorithm for neuropathic pain treatment: an evidence based proposal. Pain 118:289-305.

Franchi S, Castelli M, Amodeo G, Niada S, Ferrari D, Vescovi A, Brini AT, Panerai AE, Sacerdote P (2014) Adult stem cell as new advanced therapy for experimental neuropathic pain treatment. BioMed Res Int 2014:470983.

Fujimoto Y, Abematsu M, Falk A, Tsujimura K, Sanosaka T, Juliandi B, Semi K, Namihira M, Komiya S, Smith A, Nakashima K (2012) Treatment of a mouse model of spinal cord injury by transplantation of human induced pluripotent stem cell-derived long-term self-renewing neuroepithelial-like stem cells. Stem Cells (Dayton, Ohio) 30:1163-1173.

Gu YL, Yin LW, Zhang Z, Liu J, Liu SJ, Zhang LF, Wang TH (2012) Neurotrophin expression in neural stem cells grafted acutely to transected spinal cord of adult rats linked to functional improvement. Cell Mol Neurobiol 32:1089-1097.

Guenot M, Lee JW, Nasirinezhad F, Sagen J (2007) Deafferentation pain resulting from cervical posterior rhizotomy is alleviated by chromaffin cell transplants into the rat spinal subarachnoid space. Neurosurgery 60:919-925 (discussion 919-925).

Guo JS, Zeng YS, Li HB, Huang WL, Liu RY, Li XB, Ding Y, Wu LZ, Cai DZ (2007) Cotransplant of neural stem cells and NT-3 gene modified Schwann cells promote the recovery of transected spinal cord injury. Spinal Cord 45:15-24.

Guo X, Zahir T, Mothe A, Shoichet MS, Morshead CM, Katayama Y, Tator $\mathrm{CH}$ (2012) The effect of growth factors and soluble Nogo-66 receptor protein on transplanted neural stem/progenitor survival and axonal regeneration after complete transection of rat spinal cord. Cell Transplant 21:1177-1197.

Hama A, Sagen J (2007) Behavioral characterization and effect of clinical drugs in a rat model of pain following spinal cord compression. Brain Res 1185:117-128.

Hassannejad Z, Sharif-Alhoseini M, Shakouri-Motlagh A, Vahedi F, Zadegan SA, Mokhatab M, Rezvan M, Saadat S, Shokraneh F,
Rahimi-Movaghar V (2015) Potential variables affecting the quality of animal studies regarding pathophysiology of traumatic spinal cord injuries. Spinal Cord.

He BL, Ba YC, Wang XY, Liu SJ, Liu GD, Ou S, Gu YL, Pan XH, Wang TH (2013) BDNF expression with functional improvement in transected spinal cord treated with neural stem cells in adult rats. Neuropeptides 47:1-7.

Hofstetter CP, Holmstrom NA, Lilja JA, Schweinhardt P, Hao J, Spenger C, Wiesenfeld-Hallin Z, Kurpad SN, Frisen J, Olson L (2005) Allodynia limits the usefulness of intraspinal neural stem cell grafts; directed differentiation improves outcome. Nat Neurosci 8:346-353.

Hong JY, Lee SH, Lee SC, Kim JW, Kim KP, Kim SM, Tapia N, Lim KT, Kim J, Ahn HS, Ko K, Shin CY, Lee HT, Scholer HR, Hyun JK, Han DW (2014) Therapeutic potential of induced neural stem cells for spinal cord injury. J Biol Chem 289:32512-32525.

Hooshmand MJ, Sontag CJ, Uchida N, Tamaki S, Anderson AJ, Cummings BJ (2009) Analysis of host-mediated repair mechanisms after human CNS-stem cell transplantation for spinal cord injury: Correlation of engraftment with recovery. PLoS One 4.

Hori J, Ng TF, Shatos M, Klassen H, Streilein JW, Young MJ (2003) Neural progenitor cells lack immunogenicity and resist destruction as allografts. Stem Cells (Dayton, Ohio) 21:405-416.

Hosseini M, Karami Z, Janzadenh A, Jameie SB, Haji Mashhadi Z, Yousefifard M, Nasirinezhad F (2014) The effect of intrathecal administration of muscimol on modulation of neuropathic pain symptoms resulting from spinal cord injury; an experimental study. Emergency (Tehran, Iran) 2:151-157.

Hosseini M, Yousefifard M, Aziznejad H, Nasirinezhad F (2015) The effect of bone marrow-derived mesenchymal stem cell transplantation on allodynia and hyperalgesia in neuropathic animals: a systematic review with meta-analysis. Biol. Blood Marrow Transpl 21:1537-1544.

Hu YF, Gourab K, Wells C, Clewes O, Schmit BD, Sieber-Blum M (2010) Epidermal neural crest stem cell (EPI-NCSC)-mediated recovery of sensory function in a mouse model of spinal cord injury. Stem Cell Rev Rep 6:186-198.

Hwang DH, Shin HY, Kwon MJ, Choi JY, Ryu BY, Kim BG (2014) Survival of neural stem cell grafts in the lesioned spinal cord is enhanced by a combination of treadmill locomotor training via insulin-like growth factor-1 signaling. J Neurosci 34:12788-12800.

Iwai H, Shimada H, Nishimura S, Kobayashi Y, Itakura G, Hori K, Hikishima K, Ebise H, Negishi N, Shibata S, Habu S, Toyama Y, Nakamura M, Okano H (2015) Allogeneic neural stem/progenitor cells derived from embryonic stem cells promote functional recovery after transplantation into injured spinal cord of nonhuman primates. Stem Cells Transl Med 4:708-719.

Iwanami A, Kaneko S, Nakamura M, Kanemura Y, Mori H, Kobayashi S, Yamasaki M, Momoshima S, Ishii H, Ando K, Tanioka Y, Tamaoki N, Nomura T, Toyama Y, Okano H (2005) Transplantation of human neural stem cells for spinal cord injury in primates. J Neurosci Res 80:182-190.

Iwasaki M, Wilcox JT, Nishimura Y, Zweckberger K, Suzuki H, Wang J, Liu Y, Karadimas SK, Fehlings MG (2014) Synergistic effects of self-assembling peptide and neural stem/progenitor cells to promote tissue repair and forelimb functional recovery in cervical spinal cord injury. Biomaterials 35:2617-2629.

Johnson PJ, Tatara A, McCreedy DA, Shiu A, Sakiyama-Elbert SE (2010) Tissue-engineered fibrin scaffolds containing neural progenitors enhance functional recovery in a subacute model of SCI. Soft Matter 6:5127-5137.

Kao T, Chang LW (1977) The mechanism of spinal cord cavitation following spinal cord transection. J Neurosurg 46:197-209.

Karimi-Abdolrezaee S, Eftekharpour E, Wang J, Morshead CM, Fehlings MG (2006) Delayed transplantation of adult neural precursor cells promotes remyelination and functional neurological recovery after spinal cord injury. J Neurosci 26:3377-3389

Karimi-Abdolrezaee S, Eftekharpour E, Wang J, Schut D, Fehlings MG (2010) Synergistic effects of transplanted adult neural stem/ 
progenitor cells, chondroitinase, and growth factors promote functional repair and plasticity of the chronically injured spinal cord. J Neurosci 30:1657-1676.

Kim H, Zahir T, Tator CH, Shoichet MS (2011) Effects of dibutyryl cyclic-AMP on survival and neuronal differentiation of neural stem/progenitor cells transplanted into spinal cord injured rats. PLoS One 6 e21744.

Kim HJ, Oh JS, An SS, Pennant WA, Gwak SJ, Kim AN, Han PK, Yoon DH, Kim KN, Ha Y (2012) Hypoxia-specific GM-CSFoverexpressing neural stem cells improve graft survival and functional recovery in spinal cord injury. Gene Ther 19:513-521.

Kobayashi Y, Okada Y, Itakura G, Iwai H, Nishimura S, Yasuda A, Nori S, Hikishima K, Konomi T, Fujiyoshi K, Tsuji O, Toyama Y, Yamanaka S, Nakamura M, Okano H (2012) Pre-evaluated safe human iPSC-derived neural stem cells promote functional recovery after spinal cord injury in common marmoset without tumorigenicity. PLoS One 7 e52787.

Kumagai G, Okada Y, Yamane J, Nagoshi N, Kitamura K, Mukaino M, Tsuji O, Fujiyoshi K, Katoh H, Okada S, Shibata S, Matsuzaki Y, Toh S, Toyama Y, Nakamura M, Okano H (2009) Roles of ES cell-derived gliogenic neural stem/progenitor cells in functional recovery after spinal cord injury. PLoS One 4 e7706.

Kumamaru H, Saiwai H, Kubota K, Kobayakawa K, Yokota K, Ohkawa Y, Shiba K, Iwamoto Y, Okada S (2013) Therapeutic activities of engrafted neural stem/precursor cells are not dormant in the chronically injured spinal cord. Stem Cells (Dayton, Ohio) 31:1535-1547.

Kumru H, Soler D, Vidal J, Navarro X, Tormos J, Pascual-Leone A, Valls-Sole $J$ (2013) The effects of transcranial direct current stimulation with visual illusion in neuropathic pain due to spinal cord injury: an evoked potentials and quantitative thermal testing study. Eur. J. Pain 17:55-66.

Lee-Kubli CA, Lu P (2015) Induced pluripotent stem cell-derived neural stem cell therapies for spinal cord injury. Neural Regenerat Res 10:10-16.

Lee S-T, Chu K, Jung K-H, Kim S-J, Kim D-H, Kang K-M, Hong NH, Kim J-H, Ban J-J, Park H-K (2008a) Anti-inflammatory mechanism of intravascular neural stem cell transplantation in haemorrhagic stroke. Brain 131:616-629.

Lee S-T, Chu K, Park H-K, Jung K-H, Kim M, Lee SK, Roh J-K (2008b) New concept of neural stem cell transplantation: antiinflammatory role. International Journal of Stem Cells 1:36-42.

Lee SH, Chung YN, Kim YH, Kim YJ, Park JP, Kwon DK, Kwon OS, Heo JH, Kim YH, Ryu S, Kang HJ, Paek SH, Wang KC, Kim SU, Yoon BW (2009) Effects of human neural stem cell transplantation in canine spinal cord hemisection. Neurol Res 31:996-1002.

Li J, Lepski G (2013) Cell transplantation for spinal cord injury: a systematic review. BioMed Res Int 2013.

Liu C, Huang Y, Pang M, Yang Y, Li S, Liu L, Shu T, Zhou W, Wang X, Rong L, Liu B (2015) Tissue-engineered regeneration of completely transected spinal cord using induced neural stem cells and gelatin-electrospun poly (lactide-co-glycolide)/polyethylene glycol scaffolds. PLoS One 10.

Lowry N, Goderie SK, Adamo M, Lederman P, Charniga C, Gill J, Silver J, Temple S (2008) Multipotent embryonic spinal cord stem cells expanded by endothelial factors and Shh/RA promote functional recovery after spinal cord injury. Exp Neurol 209:510-522.

Lu P, Wang Y, Graham L, McHale K, Gao M, Wu D, Brock J, Blesch A, Rosenzweig ES, Havton LA, Zheng B, Conner JM, Marsala M, Tuszynski MH (2012) Long-distance growth and connectivity of neural stem cells after severe spinal cord injury. Cell 150:1264-1273.

Lu P, Woodruff G, Wang Y, Graham L, Hunt M, Wu D, Boehle E, Ahmad R, Poplawski G, Brock J, Goldstein LS, Tuszynski MH (2014) Long-distance axonal growth from human induced pluripotent stem cells after spinal cord injury. Neuron 83:789-796.

Luo Y, Zou Y, Yang L, Liu J, Liu S, Liu J, Zhou X, Zhang W, Wang T (2013) Transplantation of NSCs with OECs alleviates neuropathic pain associated with NGF downregulation in rats following spinal cord injury. Neurosci Lett 549:103-108.
Macias MY, Syring MB, Pizzi MA, Crowe MJ, Alexanian AR, Kurpad SN (2006) Pain with no gain: allodynia following neural stem cell transplantation in spinal cord injury. Exp Neurol 201: 335-348.

Madsen JR, MacDonald P, Irwin N, Goldberg DE, Yao G-L, Meiri KF, Rimm IJ, Stieg PE, Benowitz LI (1998) Tacrolimus (FK506) increases neuronal expression of GAP-43 and improves functional recovery after spinal cord injury in rats. Exp Neurol 154:673-683.

Mann R, Schaefer C, Sadosky A, Bergstrom F, Baik R, Parsons B, Nalamachu S, Stacey BR, Tuchman M, Anschel A, Nieshoff EC (2013) Burden of spinal cord injury-related neuropathic pain in the United States: retrospective chart review and cross-sectional survey. Spinal Cord 51:564-570.

Marineo G, Iorno V, Gandini C, Moschini V, Smith TJ (2012) Scrambler therapy may relieve chronic neuropathic pain more effectively than guideline-based drug management: results of a pilot, randomized, controlled trial. J Pain Symptom Manage 43:87-95.

Mark Richardson R, Broaddus WC, Holloway KL, Fillmore HL (2005) Grafts of adult subependymal zone neuronal progenitor cells rescue hemiparkinsonian behavioral decline. Brain Res 1032:11-22.

Moher D, Liberati A, Tetzlaff J, Altman DG (2009) Preferred reporting items for systematic reviews and meta-analyses: the PRISMA statement. Ann Intern Med 151:264-269.

Mothe AJ, Tator CH (2013) Review of transplantation of neural stem/ progenitor cells for spinal cord injury. Int J Dev Neurosci 31:701-713.

Nasirinezhad F, Hosseini M, Karami Z, Yousefifard M, Janzadeh A (2015a) Spinal 5-HT3 receptor mediates nociceptive effect on central neuropathic pain; possible therapeutic role for tropisetron. J Spinal Cord Med.

Nasirinezhad F, Hosseini M, Salari S (2015b) Anti-allodynic efficacy of NMDA antagonist peptide and noradrenaline alone and in combination in rodent neuropathic pain model. Korean $\mathrm{J}$ Pain 28:96-104.

Nemati S, Jabbari R, Hajinasrollah M, Mehrjerdi NZ, Azizi H, Hemmesi K, Moghiminasr R, Azhdari Z, Talebi A, Mohitmafi S, Dizaj AVT, Sharifi G, Baharvand H, Rezaee O, Kiani S (2014) Transplantation of adult monkey neural stem cells into a contusion spinal cord injury model in rhesus macaque monkeys. Cell $\mathrm{J}$ 16:117-130.

Nishimura S, Yasuda A, Iwai H, Takano M, Kobayashi Y, Nori S, Tsuji O, Fujiyoshi K, Ebise H, Toyama Y, Okano H, Nakamura M (2013) Time-dependent changes in the microenvironment of injured spinal cord affects the therapeutic potential of neural stem cell transplantation for spinal cord injury. Mol Brain 6:3.

Nori S, Okada Y, Yasuda A, Tsuji O, Takahashi Y, Kobayashi Y, Fujiyoshi K, Koike M, Uchiyama Y, Ikeda E, Toyama $\mathrm{Y}$, Yamanaka S, Nakamura M, Okano H (2011) Grafted humaninduced pluripotent stem-cell-derived neurospheres promote motor functional recovery after spinal cord injury in mice. Proc Natl Acad Sci USA 108:16825-16830.

Nutt SE, Chang EA, Suhr ST, Schlosser LO, Mondello SE, Moritz CT, Cibelli JB, Horner PJ (2013) Caudalized human iPSC-derived neural progenitor cells produce neurons and glia but fail to restore function in an early chronic spinal cord injury model. Exp Neurol 248:491-503.

Okada S, Ishii K, Yamane J, Iwanami A, Ikegami T, Katoh H, Iwamoto Y, Nakamura M, Miyoshi H, Okano HJ, Contag CH, Toyama Y, Okano H (2005) In vivo imaging of engrafted neural stem cells: its application in evaluating the optimal timing of transplantation for spinal cord injury. FASEB J 19:1839-1841.

Ormond DR, Shannon C, Oppenheim J, Zeman R, Das K, Murali R, Jhanwar-Uniyal M (2014) Stem cell therapy and curcumin synergistically enhance recovery from spinal cord injury. PLoS One 9 e88916.

Ottoboni L, De Feo D, Merlini A, Martino G (2015) Commonalities in immune modulation between mesenchymal stem cells (MSCs) and neural stem/precursor cells (NPCs). Immunol Lett. 
Oyinbo CA (2011) Secondary injury mechanisms in traumatic spinal cord injury: a nugget of this multiply cascade. Acta Neurobiol Exp 71:281-299.

Pallini R, Vitiani LR, Bez A, Casalbore P, Facchiano F, Di Giorgi Gerevini V, Falchetti ML, Fernandez E, Maira G, Peschle C, Parati E (2005) Homologous transplantation of neural stem cells to the injured spinal cord of mice. Neurosurgery 57:1014-1024.

Pan HC, Cheng FC, Lai SZ, Yang DY, Wang YC, Lee MS (2008) Enhanced regeneration in spinal cord injury by concomitant treatment with granulocyte colony-stimulating factor and neuronal stem cells. J Clin Neurosci 15:656-664.

Park DY, Mayle RE, Smith RL, Corcoran-Schwartz I, Kharazi AI, Cheng I (2013) Combined transplantation of human neuronal and mesenchymal stem cells following spinal cord injury. Global Spine J 3:1-6.

Parr AM, Kulbatski I, Tator CH (2007) Transplantation of adult rat spinal cord stem/progenitor cells for spinal cord injury. J Neurotrauma 24:835-845.

Parr AM, Kulbatski I, Wang XH, Keating A, Tator CH (2008a) Fate of transplanted adult neural stem/progenitor cells and bone marrowderived mesenchymal stromal cells in the injured adult rat spinal cord and impact on functional recovery. Surg Neurol 70:600-607.

Parr AM, Kulbatski I, Zahir T, Wang X, Yue C, Keating A, Tator CH (2008b) Transplanted adult spinal cord-derived neural stem/ progenitor cells promote early functional recovery after rat spinal cord injury. Neuroscience 155:760-770.

Piltti KM, Salazar DL, Uchida N, Cummings BJ, Anderson AJ (2013a) Safety of epicenter versus intact parenchyma as a transplantation site for human neural stem cells for spinal cord injury therapy. Stem Cells Transl Med 2:204-216.

Piltti KM, Salazar DL, Uchida N, Cummings BJ, Anderson AJ (2013b) Safety of human neural stem cell transplantation in chronic spinal cord injury. Stem Cells Transl Med 2:961-974.

Pomeshchik Y, Puttonen KA, Kidin I, Ruponen M, Lehtonen S, Malm T, Akesson E, Hovatta O, Koistinaho J (2015) Transplanted human induced pluripotent stem cell-derived neural progenitor cells do not promote functional recovery of pharmacologically immunosuppressed mice with contusion spinal cord injury. Cell Transplant 24:1799-1812.

Rivera FJ, Couillard-Despres S, Pedre X, Ploetz S, Caioni M, Lois C, Bogdahn U, Aigner L (2006) Mesenchymal stem cells instruct oligodendrogenic fate decision on adult neural stem cells. Stem Cells (Dayton, Ohio) 24:2209-2219.

Romanyuk N, Amemori T, Turnovcova K, Prochazka P, Onteniente B, Sykova E, Jendelova P (2015) Beneficial effect of human induced pluripotent stem cell-derived neural precursors in spinal cord injury repair. Cell Transplant 24:1781-1797.

Rowland JW, Hawryluk GWJ, Kwon B, Fehlings MG (2008) Current status of acute spinal cord injury pathophysiology and emerging therapies: promise on the horizon. Neurosurg Focus 25.

Salazar DL, Uchida N, Hamers FP, Cummings BJ, Anderson AJ (2010) Human neural stem cells differentiate and promote locomotor recovery in an early chronic spinal cord injury NODscid mouse model. PLoS One 5 e12272.

Salewski RP, Mitchell RA, Li L, Shen C, Milekovskaia M, Nagy A, Fehlings MG (2015a) Transplantation of induced pluripotent stem cell-derived neural stem cells mediate functional recovery following thoracic spinal cord injury through remyelination of axons. Stem Cells Transl Med 4:743-754.

Salewski RP, Mitchell RA, Shen C, Fehlings MG (2015b) Transplantation of neural stem cells clonally derived from embryonic stem cells promotes recovery after murine spinal cord injury. Stem Cells Dev 24:36-50.

Scholz J, Woolf CJ (2007) The neuropathic pain triad: neurons, immune cells and glia. Nat Neurosci 10:1361-1368.

Sharp K, Boroujerdi A, Steward O, Luo ZD (2012) A rat chronic pain model of spinal cord contusion injury. Methods Mol Biol 851:195-203.

Sharp KG, Yee KM, Steward O (2014) A re-assessment of long distance growth and connectivity of neural stem cells after severe spinal cord injury. Exp Neurol 257:186-204.
Sistrom CL, Mergo PJ (2000) A simple method for obtaining original data from published graphs and plots. Am J Roentgenol 174:1241-1244.

Sontag CJ, Nguyen HX, Kamei N, Uchida N, Anderson AJ, Cummings BJ (2013) Immunosuppressants affect human neural stem cells in vitro but not in an in vivo model of spinal cord injury. Stem Cells Transl Med 2:731-744.

Sun D, Gugliotta M, Rolfe A, Reid W, McQuiston AR, Hu W, Young H (2011) Sustained survival and maturation of adult neural stem/ progenitor cells after transplantation into the injured brain. $J$ Neurotrauma 28:961-972.

Tarasenko YI, Gao J, Nie L, Johnson KM, Grady JJ, Hulsebosch CE, McAdoo DJ, Wu P (2007) Human fetal neural stem cells grafted into contusion-injured rat spinal cords improve behavior. J Neurosci Res 85:47-57.

Teixeira FG, Carvalho MM, Sousa N, Salgado AJ (2013) Mesenchymal stem cells secretome: a new paradigm for central nervous system regeneration? Cell Mol Life Sci 70:3871-3882.

Teng YD, Lavik EB, Qu X, Park KI, Ourednik J, Zurakowski D, Langer R, Snyder EY (2002) Functional recovery following traumatic spinal cord injury mediated by a unique polymer scaffold seeded with neural stem cells. Proc Natl Acad Sci USA 99:3024-3029.

Tetzlaff W, Okon EB, Karimi-Abdolrezaee S, Hill CE, Sparling JS, Plemel JR, Plunet WT, Tsai EC, Baptiste D, Smithson LJ, Kawaja MD, Fehlings MG, Kwon BK (2011) A systematic review of cellular transplantation therapies for spinal cord injury. J Neurotrauma 28:1611-1682.

Tsuji O, Miura K, Fujiyoshi K, Momoshima S, Nakamura M, Okano H (2011) Cell therapy for spinal cord injury by neural stem/ progenitor cells derived from iPS/ES cells. Neurotherapeutics: the journal of the American Society for Experimental. Neurotherapeutics 8:668-676.

Tsuji O, Miura K, Okada Y, Fujiyoshi K, Mukaino M, Nagoshi N, Kitamura K, Kumagai G, Nishino M, Tomisato S, Higashi H, Nagai $\mathrm{T}$, Katoh H, Kohda K, Matsuzaki Y, Yuzaki M, Ikeda E, Toyama Y, Nakamura M, Yamanaka S, Okano H (2010) Therapeutic potential of appropriately evaluated safe-induced pluripotent stem cells for spinal cord injury. Proc Natl Acad Sci USA 107:12704-12709.

Uccelli A, Moretta L, Pistoia V (2008) Mesenchymal stem cells in health and disease. Nat Rev Immunol 8:726-736.

van Gorp S, Leerink M, Kakinohana O, Platoshyn O, Santucci C, Galik J, Joosten EA, Hruska-Plochan M, Goldberg D, Marsala S, Johe K, Ciacci JD, Marsala M (2013) Amelioration of motor/ sensory dysfunction and spasticity in a rat model of acute lumbar spinal cord injury by human neural stem cell transplantation. Stem Cell Res Ther 4:57.

Wang JM, Zeng YS, Wu JL, Li Y, Teng YD (2011) Cograft of neural stem cells and schwann cells overexpressing TrkC and neurotrophin-3 respectively after rat spinal cord transection. Biomaterials 32:7454-7468.

Wang L, Wei FX, Cen JS, Ping SN, Li ZQ, Chen NN, Cui SB, Wan Y, Liu SY (2014) Early administration of tumor necrosis factor-alpha antagonist promotes survival of transplanted neural stem cells and axon myelination after spinal cord injury in rats. Brain Res 1575:87-100.

Wright KT, El Masri W, Osman A, Roberts S, Chamberlain G, Ashton BA, Johnson WE (2007) Bone marrow stromal cells stimulate neurite outgrowth over neural proteoglycans (CSPG), myelin associated glycoprotein and Nogo-A. Biochem Biophys Res Commun 354:559-566.

Xia L, Wan H, Hao SY, Li DZ, Chen G, Gao CC, Li JH, Yang F, Wang SG, Liu S (2013) Co-transplantation of neural stem cells and Schwann cells within poly (L-lactic-co-glycolic acid) scaffolds facilitates axonal regeneration in hemisected rat spinal cord. Chin Med J 126:909-917.

Xu CJ, Xu L, Huang LD, Li Y, Yu PP, Hang Q, Xu XM, Lu PH (2011) Combined $\mathrm{NgR}$ vaccination and neural stem cell transplantation promote functional recovery after spinal cord injury in adult rats. Neuropathol Appl Neurobiol 37:135-155. 
Xu J, Fan G, Chen S, Wu Y, Xu XM, Hsu CY (1998) Methylprednisolone inhibition of TNF- $\alpha$ expression and NF-kB activation after spinal cord injury in rats. Mol Brain Res 59:135-142.

Yamane J, Nakamura M, Iwanami A, Sakaguchi M, Katoh H, Yamada M, Momoshima S, Miyao S, Ishii K, Tamaoki N, Nomura T, Okano HJ, Kanemura Y, Toyama Y, Okano H (2010) Transplantation of galectin-1-expressing human neural stem cells into the injured spinal cord of adult common marmosets. J Neurosci Res 88:1394-1405.

Yang JR, Liao CH, Pang CY, Huang LLH, Chen YL, Shiue YL, Chen LR (2013) Transplantation of porcine embryonic stem cells and their derived neuronal progenitors in a spinal cord injury rat model. Cytotherapy 15:201-208.

Yao ZG, Sun XL, Li P, Liu HL, Wu HL, Xi ZQ, Zheng ZH (2015) Neural stem cells transplantation alleviate the hyperalgesia of spinal cord injured (SCl) associated with down-regulation of BDNF. Int J Clin Exp Med 8:404-412.

Yasuda A, Tsuji O, Shibata S, Nori S, Takano M, Kobayashi $Y$, Takahashi Y, Fujiyoshi K, Hara CM, Miyawaki A, Okano HJ,
Toyama Y, Nakamura M, Okano H (2011) Significance of remyelination by neural stem/progenitor cells transplanted into the injured spinal cord. Stem Cells (Dayton, Ohio) 29:1983-1994.

Yokota K, Kobayakawa K, Kubota K, Miyawaki A, Okano H, Ohkawa Y, Iwamoto Y, Okada S (2015) Engrafted neural stem/progenitor cells promote functional recovery through synapse reorganization with spared host neurons after spinal cord injury. Stem Cell Rep 5:264-277.

Yuan N, Tian W, Sun L, Yuan R, Tao J, Chen D (2014) Neural stem cell transplantation in a double-layer collagen membrane with unequal pore sizes for spinal cord injury repair. Neural Regenerat Res 9:1014-1019.

Zhang X, Zeng Y, Zhang W, Wang J, Wu J, Li J (2007) Co-transplantation of neural stem cells and NT-3-overexpressing Schwann cells in transected spinal cord. J Neurotrauma 24:1863-1877.

Ziv Y, Avidan H, Pluchino S, Martino G, Schwartz M (2006) Synergy between immune cells and adult neural stem/progenitor cells promotes functional recovery from spinal cord injury. Proc Natl Acad Sci USA 103:13174-13179. 